\title{
A cooperative game theoretic analysis of incentives for microgrids in regulated electricity markets
}

\author{
Chiara Lo Prete* Benjamin F. Hobbs ${ }^{\dagger}$
}

January 21, 2016

\footnotetext{
* Corresponding author at John and Willie Leone Family Department of Energy and Mineral Engineering, The Pennsylvania State University, 213 Hosler Building, University Park, PA 16802, U.S.A. Email: chiaraloprete@psu.edu. Telephone: 814-8650982 .

${ }^{\dagger}$ Department of Geography and Environmental Engineering; Environment, Energy, Sustainability and Health Institute, Johns Hopkins University, 3400 North Charles Street, Ames Hall, Baltimore, MD 21218, U.S.A. Email address: bhobbs@jhu.edu.
} 


\title{
A cooperative game theoretic analysis of incentives for microgrids in regulated electricity markets
}

\begin{abstract}
We model the economic incentives for market participants to cooperate in the development of a microgrid in a small electricity network served by a regulated utility. The microgrid can provide energy, ancillary services, heat and enhanced reliability to its customers. Using the framework of cooperative game theory, assuming exchangeable utility and full public information, we quantify how microgrid development affects prices, costs and benefits for parties in the network under alternative sets of assumptions. Our analysis yields three main results. First, market failures mean that the misalignment between the social objective (market efficiency) and objectives of private parties (profit maximization and consumer surplus maximization) can incent investment in inefficient scale and types of microgrid installations. We discuss how regulators can facilitate the realization of efficient market outcomes. Second, if the regulator does not correctly anticipate the timing of microgrid introduction and does not account for it in the ratemaking process, social benefits associated with microgrid development could be lower and suboptimal investments may take place, relative to the case in which there is no regulatory lag. Third, utility customers could reap most of the benefits of microgrid introduction, if microgrids result in lower electric rates for all customers. However, when regulated prices are above the marginal cost of power provided by the utility, introducing microgrids can instead raise rates and the resulting economic losses to utility customers might exceed the economic gains to the microgrid owner and its consumers. Our study shows how the cooperative game framework can be useful to regulators and policy makers for identifying the beneficiaries of microgrid promotion policies, and for correcting the market failures in utility pricing that can distort incentives for microgrid investment.
\end{abstract}

Keywords Microgrids, electric utility, cost of service regulation, economic efficiency, cooperative game theory, incentives.

Funding for this research was provided by the National Science Foundation under NSF-EFRI grant 0835879 and the Harvard University Center for the Environment. 


\section{Introduction}

A microgrid (MG) is a group of multiple distributed generation (DG) units and loads operating as a coordinated system, connected to the main electric grid at a single point (typically, at the distribution level), and able to function in parallel with the grid or in island mode. As of 2015, 12,031 MW of total microgrid capacity have been either planned, proposed, under construction or in operation worldwide [1]. North America is the world's leading market for microgrids, with about $65 \%$ of total capacity. The majority of microgrid applications have been demonstrations and research pilots involving institutional customers. Lidula and Rajapakse [2] review microgrid test beds around the world and simulation networks in the literature.

Within the broader literature on DG (e.g., $[3,4]$ ), many studies consider optimal investment and dispatch in a microgrid. For example, Stadler et al. [5] develop the Distributed Energy Resources Customer Adoption Model to determine the optimal configuration of microgrid systems for commercial building applications in California and New York. Ahn et al. [6] formulate the economic dispatch problem of DG units for optimal operation of a microgrid, accounting for several constraints related to its stable operation in island mode. Hawkes and Leach [7], Chen et al. [8], Zhao et al. [9] and Silvente et al. [10], among others, propose different models for optimal sizing and operation schedule of a microgrid, and illustrate their approach on existing and hypothetical microgrid systems using simulation. Levron et al. [11] propose an algorithm for optimizing energy management in grid-connected microgrids with electric storage, while Comodi et al. [12] also consider thermal energy storage. Gu et al. [13] review modeling approaches for planning and energy management in combined cooling, heating and power (CCHP) microgrids. Su et al. [14] formulate a stochastic problem for energy scheduling in microgrids including renewable energy sources. Based on a real options approach, Siddiqui and Marnay [15] derive threshold fuel costs for triggering a California-based microgrid's decision to invest in and operate a natural gas DG unit under uncertainty. Montuori et al. [16] consider the integration of renewable energy and demand response in a microgrid. Justo et al. [17] compare control and energy management strategies of alternating current (ac) and direct current (dc) microgrid systems. Che and Shahidehpour [18] present a dc control system for enhancing coordination and economic operation of microgrid generation and loads, and compare simulation results from the dc and ac models for an existing microgrid at the Illinois Institute of Technology.

Other authors model technical and economic interactions between microgrids and the main electric power system, without considering impacts on all market parties or the effect of alternative market designs. For instance, Lo Prete et al. [19] quantify how microgrids may affect profitability and emissions by central generators, as well as power system reliability, in the Northwestern European electricity market. The same 
regional network is considered in Cano-Andrade et al. [20], who develop the upper level of a sustainability assessment framework to determine optimal design and operation of a power system including microgrids. Khodaei and Shahidehpour [21] present an algorithm for microgrid planning as an alternative to centralized grid generation expansion and transmission upgrades. Broder Hytowitz [22] proposes a day-ahead unit commitment problem for a microgrid that accounts for uncertainty in solar photovoltaic generation, and includes trade of energy and ancillary services with the main grid to ensure Pareto efficiency improvements for both energy systems.

Although successful MG development will critically hinge upon the established regulatory framework, few studies have addressed regulatory issues of microgrid implementation, mainly in a descriptive way. Marnay et al. [23] and Wouters [24] describe these regulatory challenges and make suggestions to overcome them, presenting successful microgrid test beds. Van Hende and Wouters [25] discuss microgrid examples and best practices in the EU and Asian markets. The potential value, opportunities and barriers to deployment for electric and thermal energy microgrids have also been investigated for the states of New York [26, 27], Minnesota [28] and California [29]. Costa et al. [30] propose a mechanism that distributes costs and benefits of MG introduction in a way that all stakeholders are better off, compared to the case in which no MG is built, and apply their methodology to a small distribution network.

The focus of this paper is on decision-making concerning the design and operations of microgrids in a market context in which retail price regulation may significantly distort those decisions, impacting the distribution of benefits and costs among market participants. Unlike earlier work, we consider how market rules influence the efficiency of microgrid development by quantifying its impacts on prices, costs and benefits of all parties in a U.S. market served by a vertically integrated electric utility (VIU), regulated based on cost of service. ${ }^{1}$ While a regulator should encourage MG development if this increases economic (or market) efficiency, often measured by the sum of surpluses for all market participants [32], price regulation based on cost of service could introduce a misalignment between social welfare maximization and the objectives of private parties (e.g., profit maximization, consumer surplus maximization) and result in market failures, defined as situations in which the realized market outcome is not efficient. Using regional market simulation models, we present scenarios in which MG development may or may not enhance economic efficiency, and discuss regulatory tools to promote or prevent their introduction. Further, while in the mechanism proposed by Costa et al. [30] all stakeholders receive a share of economic surplus that is proportional to the financial

\footnotetext{
${ }^{1}$ Publicly and privately owned VIUs serve half of the U.S. states, corresponding to approximately one third of U.S. electricity load [31]. Besides the case of regulated electricity markets, average cost pricing is also relevant in situations where the bulk power market has been deregulated, but retail competition is absent and the local distribution utility is the only power supplier at regulated rates.
} 
risk faced as a result of microgrid introduction, we calculate gains and losses of market participants in the framework of cooperative game theory with exchangeable utility (i.e., side payments). Even though the simulation results refer to a stylized power system, our analysis can be of practical use to regulators and policy makers for identifying the beneficiaries of microgrid promotion policies, and for correcting the market failures in utility pricing that can distort incentives for microgrid investment.

The rest of the paper proceeds as follows. In Section 2 we summarize relevant concepts of cooperative game theory and describe the coalitions among the players in the game, as well as assumptions, data and optimization models for each coalition. Section 3 discusses our results for five scenarios in which a misalignment between social welfare maximization and the objectives of private stakeholders may occur. Section 4 concludes, while Appendices A, B and C present technical details of our optimization models and solution approach.

\section{Methodology and data}

We study the interaction of three players (an incumbent electric utility, a private investor in a MG and residential customers potentially representing MG load) in the framework of cooperative game theory, assuming exchangeable utility and full public information [33, 34, 35]. Different subsets of players could agree to cooperate, and each coalition achieves a monetary payoff (i.e., producer or consumer surplus). For different sets of assumptions, or scenarios, we compute the payoff of each coalition under existing regulation (average cost pricing). The outcome of the grand coalition among the three players allows us to determine whether MG development, in cooperation with the regulated utility, enhances market efficiency and result in gains or losses for each party, as well as for other customers in the network. Finally, we compare the outcome of the grand coalition under existing regulation to two solution concepts frequently used in cooperative game theory, the core and the Shapley value: the goal is to determine what side payments between the parties (if any) would be needed to bring the existing solution into the core or in line with the Shapley value, and discuss what policies a regulator might put in place to achieve this outcome. In the analysis, we consider a simple system to illustrate the various scenarios and the need for policies that align market incentives with social benefits and costs, and refer to this system below as the ideal network.

After providing some background on concepts of cooperative game theory that are relevant for this analysis (Section 2.1), we describe the characteristics of our ideal network and the coalitions formed by the three players (Section 2.2), the assumptions and data used to simulate each coalition (Section 2.3), the 
optimization models for the different coalitions (Section 2.4) and the scenarios (Section 2.5). Additional details on each model's formulation and our solution approach are presented in Appendices A, B and C.

\subsection{Cooperative games and two solution concepts: the core and the Shapley value}

A player in a game is an autonomous unit making decisions to pursue an objective that in our analysis is quantified in monetary terms (e.g., profit maximization). When players can coordinate their actions and make binding agreements resulting in outcomes that would not be possible if they acted separately, the game is defined as cooperative and the subset of players making binding agreements is known as a coalition [36]. In a cooperative game with $n$ players, $2^{n}$ coalitions are possible. For example, in a game with three players, eight coalitions are possible, including $\{\emptyset\}$, the empty coalition, and $\{N\}$, the grand coalition of $n$ players acting in concert.

In a cooperative game, each coalition $S$ achieves a monetary payoff for its members, the value $v(S)$. If the value of a joint coalition is greater than or equal to the sum of surpluses earned by the individual players or any union of disjoint coalitions, the game is said to be superadditive. ${ }^{2}$ In a game with exchangeable utility, the value of the grand coalition, $v(N)$, can be divided among its members in any mutually agreeable fashion, and transferred from one party to the other via side payments: the question is how to allocate the total payoff among the parties. Different solution concepts have been proposed to determine the amount each player should receive; the ones considered in our analysis are the core and the Shapley value.

The core [37] is defined as the "set of payoff configurations that leave no coalition in a position to improve the payoffs to all of its members" [38], and satisfies conditions of individual rationality and group rationality. Individual rationality prescribes that each player's gains from cooperation should be greater than or equal to zero (so that no player receives a payoff from cooperation that is lower than what he could get by acting alone). Group rationality states that the sum of gains from cooperation for the members of coalition $S$ should be positive (so that no coalition receives a payoff that is lower than the sum of each member's payoffs by acting alone); in addition, the sum of the gains of all players should equal the value of the grand coalition.

For each participant in the cooperative game, it is possible to define a range of gains from cooperation satisfying individual and group rationality constraints, with a lower bound of zero and a positive upper bound; the core of the cooperative game is the set of solutions that simultaneously satisfy those constraints

\footnotetext{
${ }^{2}$ Superadditivity applies to all our scenarios, with the exception of Scenario III and V.
} 
for all players. The core is empty when, for at least one player in the game, the lower bound of the range of gains is negative and the upper bound is zero: this means that, if coalition $S$ has formed and player $i$ is the last one to join it, the marginal contribution of that player to the coalition is negative and its participation to the coalition is not beneficial. The core allows the researcher to narrow down a possible range of gains from cooperation (or, alternatively, a set of acceptable payoffs) for each player, but does not distinguish one point of the set as preferable to another: therefore, it typically does not return a unique answer.

The Shapley value relies on the value concept proposed in [39]. A value function $\phi$ defines a tuple of real numbers $\phi(v)=\left(\phi_{1}(v), \phi_{2}(v), \ldots, \phi_{n}(v)\right)$, where $\phi_{i}(v)$ represents the value to player $i$ from playing in the game. The Shapley value can be calculated for any superadditive game with a finite number of players and, contrary to the core, is unique. ${ }^{3}$ The Shapley value allocation for player $i$ in an $n$-person game, $\phi_{i}(v)$, is defined as follows:

$$
\phi_{i}(v)=\sum_{S \in N} \frac{(n-s) !(s-1) !}{n !}[v(S)-v(S-i)] \quad \forall i=1, \ldots, n
$$

where:

$n \quad$ number of players in the game

$N \quad$ set of players

$s \quad$ number of players in coalition $S$

$S \quad$ coalition of players

$v(S) \quad$ value of coalition $S$

$v(S-i) \quad$ value of the coalition formed by all members of $S$ but $i$

If coalition $S$ has formed and player $i$ is the last one to join that coalition, his marginal contribution to the coalition is given by the term $[v(S)-v(S-i)]$; therefore, the Shapley value allocation remunerates each player based on a weighted sum of its marginal contributions to each coalition of interest. In the electricity economics literature, the Shapley value has been used to allocate the cost of transmission systems [40, 41].

\subsection{Coalitions}

We assume that an investor-owned vertically integrated utility, regulated based on cost of service, currently satisfies the real and reactive power residential load of a small network. At the transmission level, the network is composed of three nodes or buses (A, B and C), connected in a triangle by lines with equal electrical impedance. Each transmission node feeds several distribution nodes, that are not linked to each other; residential customers are connected to the grid at this lower voltage level. Customers at distribution

\footnotetext{
${ }^{3}$ The existence and uniqueness of the function $\phi(v)$ in a game with $n$ players results from four axioms, described in [36].
} 
node $\mathrm{D}$, connected to $\mathrm{A}$, are facing growing energy demand. The utility could invest in new generation and distribution capacity to serve all residential customers of the network, or a microgrid could be developed to serve customers at node $\mathrm{D}$, or some combination of the two.

This setting can be represented as a game with three players (the VIU, the private investor in the MG and the consumers at node D) and seven non-empty coalitions. ${ }^{4}$ We now provide a general introduction to all of them; the next section presents a more detailed description of each coalition.

First, three one-player coalitions are formed when each player acts independently. The value of Coalition $\{V I U\}$ is equal to the utility's profit when it satisfies the real and reactive power load of the entire network. Since the utility is regulated based on cost of service, its profit is in fact constrained to zero, because the regulator only allows a revenue amount that is deemed appropriate to cover prudent expenses and a rate of return on shareholders' investment, as explained in Section 2.3.1. The value of Coalition \{Private investor\} is also equal to zero: the private investor does not enter the market if no cooperation with the utility or the consumers is achieved. Finally, the value of Coalition $\{\mathrm{D}\}$ is equal to the surplus of the consumers at node D when they rely on the VIU for real and reactive power, and supply their thermal load locally with natural gas furnaces. Although this may appear to be a situation of cooperation between the utility and the consumers, we assume that the former is legally obliged to offer service to the latter on an average cost basis.

Three additional coalitions are formed by concatenating players in pairs, while the seventh coalition is the grand coalition of all players acting in concert. We can think of two and three player coalitions in terms of different services provided to residential customers at node D (i.e., electricity, heat, reliability or all of them).

The value of Coalition $\{$ VIU, D $\}$ is given by the sum of the utility's profit and the surplus of customers at distribution node $\mathrm{D}$ when they are served by the utility. The utility's problem is the same as the one outlined in Coalition $\{\mathrm{VIU}\}$, while the surplus of consumers at node $\mathrm{D}$ is defined as in Coalition $\{\mathrm{D}\}$. In other words, the two players make the same decisions as when they act on their own. This results from the fact that the utility is compelled to offer service at average cost to all consumers (whether or not it cooperates with them).

The value of Coalition $\{$ VIU, Private investor is the sum of profit for the utility and the private investor, if the MG only provides power to residential customers. The utility could cooperate with the private investor to satisfy the electric load of customers at node D because distributed generation is less subject to siting limitations than new centralized power plants. In this case, the utility relies on the MG for local provision

\footnotetext{
${ }^{4}$ An alternative configuration is a game in which the utility and customers who are served by the utility (but could not be part of the $\mathrm{MG}$ ) act as a single player. This game does not yield substantially different results than the ones in our base scenario (Scenario I).
} 
of energy, and remunerates electricity sales and ancillary services to the grid. However, since consumers at node $\mathrm{D}$ are not part of the coalition, they continue to supply their thermal load with natural gas furnaces and Combined Heat and Power (CHP) capacity is not needed in the MG. The utility provides power to the other nodes, whose customers also satisfy their thermal load autonomously.

Instead of relying on the VIU, customers at node D could cooperate with the private investor to satisfy their electric and thermal load through cogeneration. MG generators would also supply reactive power needed by those consumers on a local basis. The value of Coalition $\{$ Private investor, D $\}$ is the sum of the private investor's profit and the surplus of customers representing the MG load component. We assume that the utility can effectively prevent the MG from selling excess power and ancillary services to the grid, while still being required to act as a back-up supplier for microgrid customers.

The seventh (or grand) coalition is formed when all players act in concert. In this case, the private investor cooperates with both the utility and local customers at node D, with distributed generators satisfying their electric and thermal load. The value of Coalition $\{$ VIU, Private investor, $D\}$ is the sum of surpluses for the three players.

It is worth emphasizing that each coalition has an impact on the payoffs of not just its members, but also other players outside the coalition. For example, a coalition between the private investor and the utility affects the surplus of consumers at node D (who are players in the game but do not join this particular coalition), because they are charged rates equal to the VIU's average cost, which is affected by its coalition with the private investor. Moreover, parties not participating in the game are also impacted. For example, consumers that are not part of the MG cannot join or block any coalition in the game, but their surplus is affected by price changes induced by each coalition, relative to the case in which the utility serves all customers. We consider impacts on all parties when assessing market efficiency.

\subsection{Assumptions and data}

This section outlines assumptions and data for each coalition. We do not consider Coalition \{Private investor\}, since the private investor will not enter the market if no cooperation is achieved with either the utility or consumers at node D. In describing each joint coalition, we also discuss payments and charges that do not affect the value of the coalition, but affect how the parties in the coalition split that value. These represent income transfers from one party in the coalition to another, and could be tuned by the regulator to move the solution under existing regulation into the core of the cooperative game or to achieve the Shapley value. 


\subsubsection{Coalition $\{$ VIU $\}$}

We assume that the utility owns a $400 \mathrm{MW}$ coal steam generating unit and a $250 \mathrm{MW}$ combined cycle gas turbine power plant, respectively at nodes B and C, and provides reactive power through 0.9 MVar capacitor banks sited near reactive power loads. ${ }^{5}$ To satisfy node D's additional real power load, the utility can invest in new combustion turbine capacity, which can only be built at node $\mathrm{C}$ due to siting limitations. Table 1 details cost and technical characteristics of existing and new central generators.

Table 1: Assumed central power plant costs and technical characteristics

\begin{tabular}{|c|c|c|c|}
\hline & Coal conventional & $\begin{array}{c}\text { Natural Gas } \\
\text { Combined Cycle }\end{array}$ & $\begin{array}{c}\text { Natural Gas } \\
\text { Combustion Turbine }\end{array}$ \\
\hline Existing nameplate capacity (MW) & 400 & 250 & n.a. \\
\hline Capital cost $(\$ / \mathrm{kW})$ & 1,160 & 609 & 653 \\
\hline Fuel cost (\$/MBtu) & 2.38 & 4.87 & 4.87 \\
\hline Heat rate $(\mathrm{Btu} / \mathrm{kWh})$ & 9,203 & 7,194 & 10,786 \\
\hline Marginal fuel cost (\$/MWh) & 21.90 & 35.05 & 52.55 \\
\hline Variable non-fuel O\&M cost (\$/MWh) & 4.69 & 2.11 & 3.65 \\
\hline $\mathrm{CO}_{2}$ emission rate (ton/MWh) & 0.876 & 0.388 & 0.596 \\
\hline Ten-minute ramp capability ( $\%$ of capacity) & 0.08 & 0.45 & 1 \\
\hline Black-start capability (binary) & No & No & Yes \\
\hline Lifetime (years) & 40 & 30 & 20 \\
\hline
\end{tabular}

We also assume that the utility is required to maintain an installed reserve margin of $15 \%$ above peak power generation in the network. To meet this requirement, the VIU can either build capacity or buy reserves at an assumed cost of $\$ 164 / \mathrm{MW}$-day. ${ }^{6}$ The utility is also required to maintain operating reserves equal to $7 \%$ of total load, and the black-start requirement is equal to $6 \%$ of existing capacity. Finally, the VIU can invest in new capacitor banks, at a cost of $\$ 5,304$ per capacitor.

Transmission capacity is constrained along transmission arcs A-B and A-C, and along the distribution line connecting A to D. Moreover, transmission and distribution losses occur on the lines of the network. Table 2 reports the assumed network capacity constraints and resistance losses over the arcs of the network. The utility can expand the ability of the distribution network to move power from the high voltage grid to consumers at a capital cost of $\$ 150 / \mathrm{kW}[47] . \mathrm{CO}_{2}$ emissions from power generation are subject to a carbon tax equal to $\$ 20 /$ ton.

Electricity demand is elastic in each load period and at every node (see Appendix C). Figure 1 represents existing generation, transmission and distribution capacity, and peak load at each node in our ideal network.

\footnotetext{
${ }^{5}$ Our choice of power plant size for existing generation units is based on typical values from [42].

${ }^{6}$ This reference value is the 2010 system-wide weighted average price for the PJM capacity market [46].
} 
Table 2: Assumed transmission and distribution capacity constraints, and resistance losses

\begin{tabular}{ccc}
\hline Arc & $\begin{array}{c}\text { Transmission constraints } \\
(\mathrm{MW})\end{array}$ & $\begin{array}{c}\text { Resistance loss coefficients } \\
(1 / \mathrm{MW})\end{array}$ \\
\hline \hline A-B & 115 & 0.0013 \\
A-C & 140 & 0.0013 \\
B-C & n.a. & 0.0009 \\
A-D & 10 & 0.01 \\
\hline
\end{tabular}

Figure 1: Power network

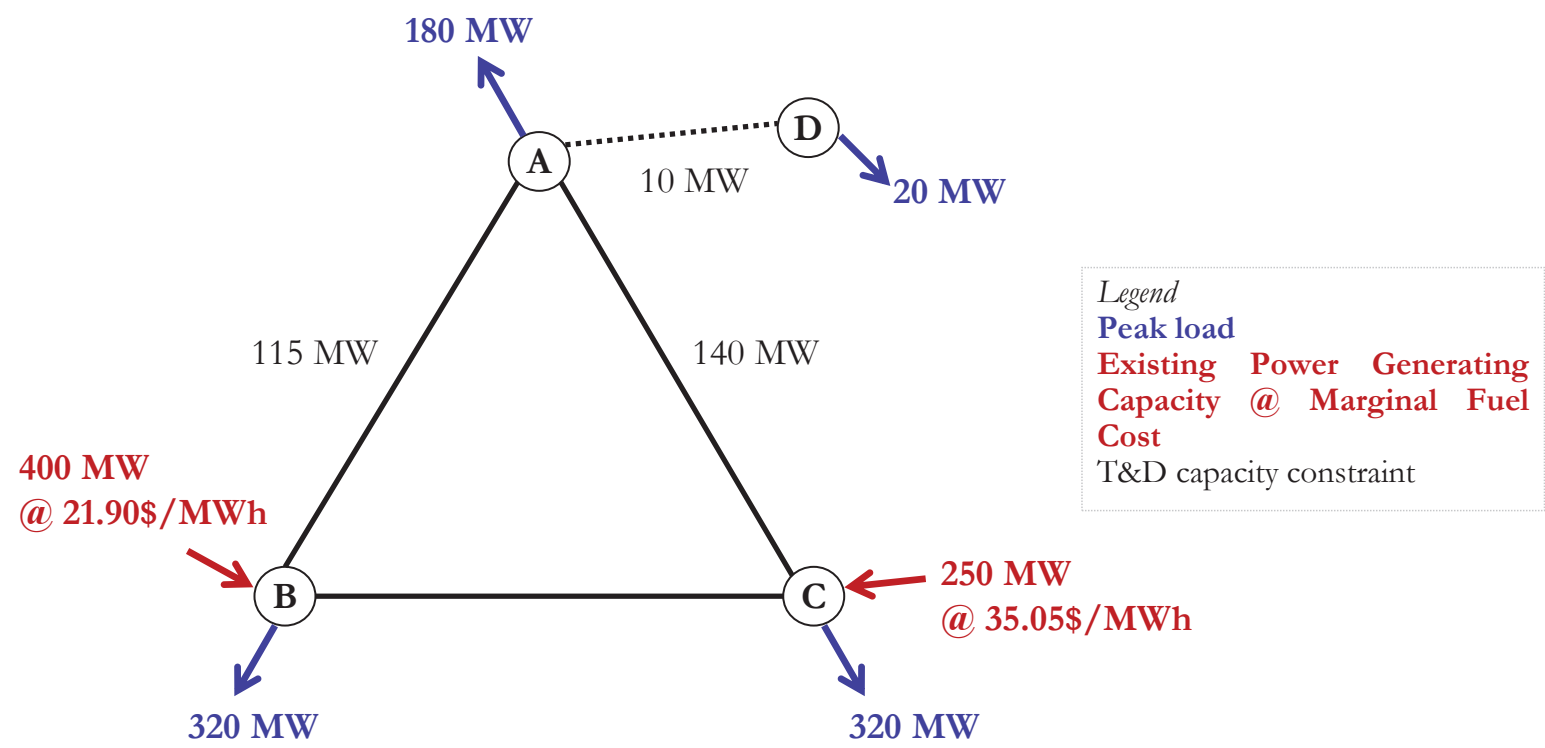

Electricity retail prices for a utility regulated based on cost of service track its average costs and include a rate of return (ROR) on shareholders' investment, that is deemed appropriate by the regulator. In the U.S., entities responsible for supervising this process at the state level are public utility commissions (PUCs). Ratemaking occurs in proceedings known as rate cases, whose frequency varies but is usually between three to four years [48]. We assume that rate cases occur every four years, and divide our rate-making process into three steps:

1. The first step is to determine the rate of return and the rate base, corresponding to the book value of the utility's assets (existing assets' cost, net of depreciation, plus new assets). For existing assets, the rate base includes the book value of generating capacity, capacitor banks and transmission and distribution (T\&D) capacity. Straight-line depreciation over each asset's lifetime is assumed. Given the book value of existing generating capacity, the book value of existing transmission and distribution capacity is determined using an average of typical (T\&D assets/Generation assets) ratios for regulated 
utilities [49].

We assume that the regulator establishes a return on investment equal to $10 \%$, a rate that is consistent with the ones allowed in states with traditional utility regulation [50]. The product of the existing assets' rate base and the ROR is the utility's total allowed return on investment (Table 3).

The value of new assets, including the new combustion turbines, capacitor banks and distribution capacity expansion, is added to the book value of existing assets. Instead of following the straight-line depreciation approach adopted for existing assets, we calculate the annual economic cost (or annualized capital cost) of each new capital item to ensure consistency between revenue requirement and the way in which the utility calculates its annual profits (Table 3 ). The annual economic cost is obtained by dividing the value of capital by an annualization factor $\frac{(1+r)^{n}-1}{r(1+r)^{n}}$, where $r$ is the assumed discount rate (10\%) and $n$ is the useful life of the new asset. The annual economic cost of capital can be thought of as a combination of the allowed return on investment and an "implied" depreciation, which is different from the amount obtained with straight-line depreciation.

2. The second step consists in calculating the utility's revenue requirement, the revenue amount considered necessary to cover expenses and the allowed rate of return. The formula for the revenue requirement is:

RevenueRequirement $=$ RateBase $*$ ROR + DepreciationExpenses + OperatingExpenses + Taxes

In our analysis, operating expenses include costs for fuel, $\mathrm{CO}_{2}$ emission permits, capacity credits and O\&M, while taxes are not considered. The revenue requirement in our base scenario is presented in Table 3.

3. The regulated retail price for electricity is obtained as: ${ }^{7}$

RegulatedPrice $=\frac{\text { RevenueRequirement }}{\text { Sales }}$

We assume that the regulated price of power is the same at every node served by the utility, although their marginal costs of supply might differ.

\footnotetext{
${ }^{7}$ Real-world complexities may include differentiation among customer classes, time-of-use rates and two-part tariffs. For clarity of the results, we abstract from these complexities and assume that the simplest rate structure, capturing the basic phenomenon of average cost-based regulation, applies to all end users.
} 
Table 3: Calculation of utility's average cost-based rates - Scenario I

\begin{tabular}{|c|c|c|c|c|}
\hline & & & oalitions & \\
\hline & $\begin{array}{c}\{\mathrm{VIU}\}, \\
\{\mathrm{D}\}, \\
\{\mathrm{VIU}, \mathrm{D}\} \\
\end{array}$ & $\{$ VIU, Pr. inv. $\}$ & $\{$ Pr. inv., D $\}$ & $\{$ VIU, Pr. inv., D $\}$ \\
\hline Utility's annual sales ( $G W h)$ & & & & \\
\hline Node A & 1,241 & 1,244 & 1,245 & 1,245 \\
\hline Node B & 2,209 & 2,215 & 2,215 & 2,215 \\
\hline Node C & 2,209 & 2,215 & 2,215 & 2,215 \\
\hline Exports to Node D (net of losses) & 137 & 53 & 16 & 3 \\
\hline Total sales $(a)$ & 5,799 & 5,728 & 5,692 & 5,679 \\
\hline Operating expenses (\$K) & & & & \\
\hline Generation costs & 203,032 & 195,190 & 194,755 & 193,116 \\
\hline $\mathrm{CO}_{2}$ emission permits & 81,505 & 79,603 & 78,740 & 78,234 \\
\hline Cost of reserves & 4,442 & 4,271 & 4,161 & 4,274 \\
\hline $\begin{array}{l}\text { Payments to the } \mathrm{MG} \text { for } \\
\text { ancillary services and reserves }\end{array}$ & - & 1,686 & - & 1,297 \\
\hline Imports from Node D & - & 403 & - & 549 \\
\hline Total operating expenses $(b)$ & 288,979 & 281,156 & 277,658 & 277,472 \\
\hline Rate base (existing assets, $\$ \mathrm{~K}$ ) & 593,466 & 593,466 & 593,466 & 593,466 \\
\hline Allowed rate of return & 0.10 & 0.10 & 0.10 & 0.10 \\
\hline $\begin{array}{l}\text { Allowed return on investment } \\
\text { (existing assets, } \$ \mathrm{~K})(c)\end{array}$ & 59,346 & 59,346 & 59,346 & 59,346 \\
\hline $\begin{array}{l}\text { Depreciation expenses } \\
\text { (existing assets, } \$ \mathrm{~K})(d)\end{array}$ & 16,915 & 16,915 & 16,915 & 16,915 \\
\hline $\begin{array}{l}\text { Annualized capital cost } \\
\text { (new assets, } \$ \mathrm{~K})(e)\end{array}$ & 22,826 & 19,653 & 20,210 & 19,740 \\
\hline Customer charge $(\$ K)(f)$ & - & -9 & -9 & -9 \\
\hline Demand charge $(\$ \mathrm{~K})(g)$ & - & -566 & -544 & -544 \\
\hline $\begin{array}{l}\text { Revenue requirement }(\$ \mathbf{K}) \\
(h=b+c+d+e+f+g)\end{array}$ & 388,067 & 376,496 & 373,576 & 372,921 \\
\hline Regulated price (\$/MWh) $(h / a)$ & 66.9 & 65.7 & 65.6 & 65.7 \\
\hline
\end{tabular}




\subsubsection{Coalition $\{D\}$}

Residential customers at node D have an elastic demand for electricity. The parameters of the inverse power demand function at each node are derived assuming a short-run price elasticity of -0.13 [51] and linear demand functions at the regulated price-quantity pair.

Heat demand for space heating purposes is proportional to electricity demand. Based on data from the 2005 U.S. Residential Energy Consumption Survey [52], we calculate two ratios. For summer hours, we divide the annual average natural gas consumption for water heating per household by the annual average electricity consumption per household. For winter hours, we divide the annual average natural gas consumption for space and water heating per household by the annual average electricity consumption per household. The heat load in every period is obtained by multiplying the electricity load by the relevant ratio (4.38 MBtu/MWh in the summer and 6.48 MBtu/MWh in the winter). The price of natural gas for heat generation is equal to $\$ 12.22 / \mathrm{MBtu}$, the 2011 average price of natural gas delivered to U.S. residential customers [53].

We assume that residential customers would be willing to pay to avoid sustained power interruptions. Campbell [54] reports a system average interruption duration index (SAIDI, i.e., the average amount of time per year that power supply to a customer is interrupted) of 240 minutes per customer in the U.S. Centolella et al. [55] estimate an average cost for residential consumers of $2005 \$ 7.21$ (equivalent to $2014 \$ 8.78$ ) per three-hour outage in a year. Based on this estimated outage cost and duration, we derive the annual cost of power interruptions for residential customers at node D: this is equal to $\$ 327 \mathrm{~K}$, about $3.5 \%$ of their electric bill.

\subsubsection{Coalition $\{$ VIU, D $\}$}

The data used to simulate the utility's problem is the same as the one presented for Coalition $\{$ VIU\}; the assumptions for electric and heat demand, and for the price of natural gas for residential customers at node $\mathrm{D}$ are the same as those presented for Coalition $\{\mathrm{D}\}$.

\subsubsection{Coalition \{VIU, Private investor\}}

As of today, there is no typical size (intended as electric generating capacity) for a microgrid, as its actual size varies depending on the scope. We assume that the MG developed by the private investor in cooperation with the VIU is sized to meet the peak electric load requirements for node D, equal to about $20 \mathrm{MW}$. This value is within the range of most existing MG installations. Note that the generating capacity of the MG is a decision variable for the private investor. 
MG capital costs also vary considerably, depending on the installed distributed generation technology. In this coalition, we assume that all DG units are natural gas reciprocating engines not equipped with CHP capability; table 4 details their characteristics. Electricity is generated within the MG or purchased from the utility and conveyed to local customers. Heat is instead self-supplied by local customers, at a natural gas price of $\$ 12.22 / \mathrm{MBtu}$.

Capital investments in load controllers, generator controllers and communication systems represent a relevant fraction of the costs for building the MG and connecting it to the main grid. Table 5 references values from the existing literature.

Table 4: Assumed characteristics of natural gas reciprocating engines

\begin{tabular}{lc}
\hline Capacity $(\mathrm{kW})$ & 200 \\
Capital cost $(\$ / \mathrm{kW})$ & 900 \\
Maintenance cost $(\$ / \mathrm{kWh})$ & 0.015 \\
Electrical efficiency $(\%)$ & 29.5 \\
Lifetime & 20 \\
\hline Source: Marnay et al. [56].
\end{tabular}

Table 5: Assumed investment needs for the MG

\begin{tabular}{lcc}
\hline Device & Quantity & Investment cost $(\$)$ \\
\hline \hline Central controller & 1 & 20,886 \\
Generator controller & 1 for each generator & 2,172 \\
Load controller & 1 for each load & 1,414 \\
Communication system & 1 & 23,949 \\
\hline \multicolumn{2}{l}{ Source: values in $€$ from Costa et al. [30] were converted to $\$$ using the } \\
2011 average $\$ / €$ exchange rate.
\end{tabular}

Being fully integrated with utility operations, if local generation exceeds customer requirements the MG can export power to the high voltage grid at the utility's avoided cost, ${ }^{8}$ equal to $\$ 52.55 / \mathrm{MW}$ (the marginal cost of generation of the natural gas combustion turbines). The MG is also remunerated by the VIU for additional services provided to the grid. First, since its capacity contributes to lowering peak load, the utility's capacity could be reduced, without affecting the benchmark level of grid reliability. We assume the private investor receives the utility's cost of capacity (\$164/MW-day).

Provision of ancillary services to the main grid also determines a reduction in the utility's direct costs for these services. Distributed generators represent an alternative to the utility's capacitor banks and can supply reactive power close to where consumption occurs. We assume the private investor receives an annual payment of $\$ 3,919 /$ MVar-year [57], applied to the DG rated MVar capacity (equal to $75 \%$ of the installed

\footnotetext{
${ }^{8}$ Under the Public Utility Regulatory Policy Act (PURPA), utilities were required to buy power from Qualifying Facilities (or QFs, defined as cogenerators and small power producers having a maximum size of 80 MW and using renewable energy waste as their primary fuel input) at their avoided cost: this rate reflected the incremental capital and operating cost the utility would have incurred to generate or purchase the energy supplied by the QF.
} 
MW capacity). The MG can also provide black start capacity and operating reserves. For black start, the private investor receives an annual payment of $\$ 1,595 / \mathrm{MW}$-year, applied to the network's MW rating, while operating reserves are priced at $\$ 16.44 / \mathrm{MW}$-hour [58].

Recent studies have acknowledged the need to review and improve the design of standby rates for services provided by the utilities to on-site generation [59]. We assume the private investor is subject to four types of charges: customer charges, demand charges, energy consumption charges and connection charges. The customer charge is a fixed monthly fee for connecting to the power grid, and is equal to $\$ 750$ per month [60]. The monthly demand charge is assessed against the peak power consumption of local customers, and calculated multiplying a demand charge rate of $\$ 2.33 / \mathrm{kW}$ [60] by peak local consumption (generation plus imports from the main grid). The private investor is also subject to energy consumption charges in case the MG cannot entirely satisfy on-site demand, or at times when power purchases are cheaper than distributed generation. Customer charges, demand charges and energy consumption charges represent an income transfer from the private investor to the utility.

Finally, the private investor is subject to a one-off charge for interconnection to the grid. In general, connection charges vary depending on the impact of new generating capacity on the existing network, and are calculated on a case-by-case basis [61]. They may include the costs for connecting an independent power producer (IPP) to the nearest point in the distribution network (for example, to install equipment designed to allow power flow reversal on the feeders), as well as any other up-front costs associated with upgrades of the distribution network induced by the IPP. Knight et al. [62] report direct costs of interconnection equal to $5-10 \%$ of total installation costs for distributed generation systems; in our paper, we assume they are equal to $10 \%$ of the annualized capital cost for installing the MG. For low levels of DG penetration, there are no incremental costs for upgrading existing network assets [63]; therefore, we do not consider these costs in our analysis. Connection charges represent a real cost for the private investor, and not an income transfer to the utility.

Since microgrids can operate in island mode, contrary to Coalition $\{\mathrm{D}\}$ and $\{$ VIU, D $\}$ customers at node $\mathrm{D}$ do not experience any power interruptions in case of outages in the main electric grid. Microgrids may provide additional reliability benefits to other grid customers, if they allowed faster power system restoration after a blackout [64]. However, it is still unclear whether or not microgrids can be configured to do this. Therefore, in our analysis we quantify reliability benefits to customers at node D (equal to their avoided cost of a three-hour per year power outage), but not potential reliability benefits to other grid customers. 


\subsubsection{Coalition Private investor, D}

The main difference with the previous coalition is that the private investor builds distributed generation capacity able to satisfy both the electric and thermal load of customers at node D. The characteristics of the MG units are the same as the ones presented in Tables 4 and 5, with the exception of the capital cost of natural gas reciprocating engines, which increases from $\$ 900 / \mathrm{kW}$ to $\$ 1200 / \mathrm{kW}$ [56] to accommodate heat recovery for CHP.

We assume that MG customers pay an electricity price such that the private gains (or losses) from the grand coalition are split equally between them and the private investor. This result could be achieved through a profit-sharing mechanism, similar to the ones in the Energy Performance Contracts between Energy Service Companies (ESCOs) and their customers. The MG can also import electricity, as needed, at the regulated price of power. Residential customers can supply their own heat, at a natural gas price of $\$ 12.22 / \mathrm{MBtu}$, or purchase heat from the MG investor at a $20 \%$ discount. The MG is subject to the same charges described for Coalition \{VIU, Private investor\}, although in this case they do not represent a transfer between parties in the same coalition. Finally, similarly to Coalition \{VIU, Private investor\}, we assume that the MG has islanding capability and provides reliability benefits to its customers (equal to their avoided cost of a threehour per year power interruption).

\subsubsection{Coalition \{VIU, Private investor, D \}}

The data used to simulate the grand coalition is the same as for Coalition \{VIU, Private investor\}, but includes cogeneration by the distributed generation units in the MG, as in Coalition \{Private investor, D\}. Electricity is generated and distributed within the MG, or purchased from the utility and then conveyed to local residential customers. Heat is generated within the MG, in proportion to the amount of electricity produced, or self-supplied by local customers at a natural gas price of $\$ 12.22 /$ MBtu.

Like Coalition \{Private investor, D\}, MG customers pay an electricity price such that the private gains (or losses) from the grand coalition are split in equal parts between them and the private investor, and purchase heat from CHP operation of the MG at a $20 \%$ discount, relative to the cost of supplying their own heat.

\subsection{Optimization models}

For each coalition in Section 2.3, we derive a model determining the optimal investment (in generation capacity, distribution capacity and capacitor banks), operations (dispatch, power flows and loads) and total 
costs. The objective function of each optimization model represents the value of the coalition; charges and payments described in Section 2.3 are included, when these are a transfer from one party within the coalition to or from a party outside the coalition. In this section, we describe the models in general terms. Their formulation is presented in Appendix A, while the nomenclature in Appendix B provides a list of variable and parameter definitions; our proposed solution approach is outlined in Appendix C.

In Coalition $\{$ VIU\}, the utility's goal is to maximize profit, subject to Kirchhoff's laws, transmission and distribution capacity limits, generator and CHP constraints, and demand for power, capacity, reactive power and heat. Since the utility is regulated based on cost of service, its profit is in fact constrained to zero, as discussed in Section 2.2. In Coalition $\{\mathrm{D}\}$, the consumers' objective is to maximize surplus, given by the gross benefit associated with electricity consumption (i.e., the integral of their demand curve for energy), minus expenditures for electricity and heat generation, and minus the cost of a three-hour per year power interruption. In Coalition $\{$ VIU, D $\}$, the utility's model is the same as the one in Coalition $\{$ VIU $\}$, while consumer surplus is as in Coalition $\{\mathrm{D}\}$.

Coalition \{VIU, Private investor $\}$ also maximizes profits, subject to network and generator constraints. However, while the regulated utility's profit is zero, the private investor is not subject to cost-of-service regulation and receives the regulated power price for its sales to local customers. Given the regulated price, the private investor can earn a profit or operate at a loss. In the latter case, the value of the coalition is set to zero: this is equivalent to assuming that no utility-sponsored MG is built, if unprofitable. As previously noted, a key difference with respect to the next two coalitions is that there are no heat sales to consumers at node D.

For Coalition \{Private investor, D\}, we present the joint model of the private investor and the consumers at distribution nodes, as well as the model for the utility. The reason for presenting a model for a nonmember of the coalition is that, unlike most cooperative game analyses, the value of Coalition \{Private investor, D\} depends on the utility's actions. The utility and the microgrid take decisions separately, but each decision influences what the other party does in reaction and affects each other's surplus; as a result, it is necessary to consider the utility's problem as well. The goal of the private investor and customers at node $\mathrm{D}$ is is to maximize the gross benefit of electricity consumption at the distribution nodes, minus costs for generation, power imports, new installed capacity and connection to the grid. The objective function is subject to Kirchhoff's Current Law at the distribution nodes, plus generator and load constraints in the MG. On the other hand, the utility's goal is to maximize profits, subject to network and central generation capacity constraints. No power is exported from the MG to the main grid, while distribution expansion represents only a parameter for the MG, as it is determined in the VIU's problem. Finally, the MG treats 
the regulated electricity price as fixed, while electricity exports and MG generation are given in the VIU's problem.

The objective of Coalition $\{$ VIU, Private investor, D $\}$ is to maximize the total surplus of the three players, subject to network and generator constraints. The objective function includes the gross benefit of electricity consumption at the distribution nodes and revenues from power sales at all nodes, minus costs for generation, reserves, new installed capacity and MG connection to the grid, depreciation expenses and allowed return on investment.

\subsection{Scenarios}

The coalitions of the cooperative game among the regulated utility, the private investor and residential customers at a distribution node are simulated under five scenarios. These differ by underlying assumptions and describe instances in which a misalignment between social welfare maximization and the objectives of private stakeholders may occur. Figure 2 schematically represents this misalignment from the point of view of the regulator (the columns of the table), versus the point of view of two stakeholders (the rows of the table): a private investor in a MG and potential MG customers at a distribution node.

Figure 2: MG development: regulator's vs. private parties' point of view

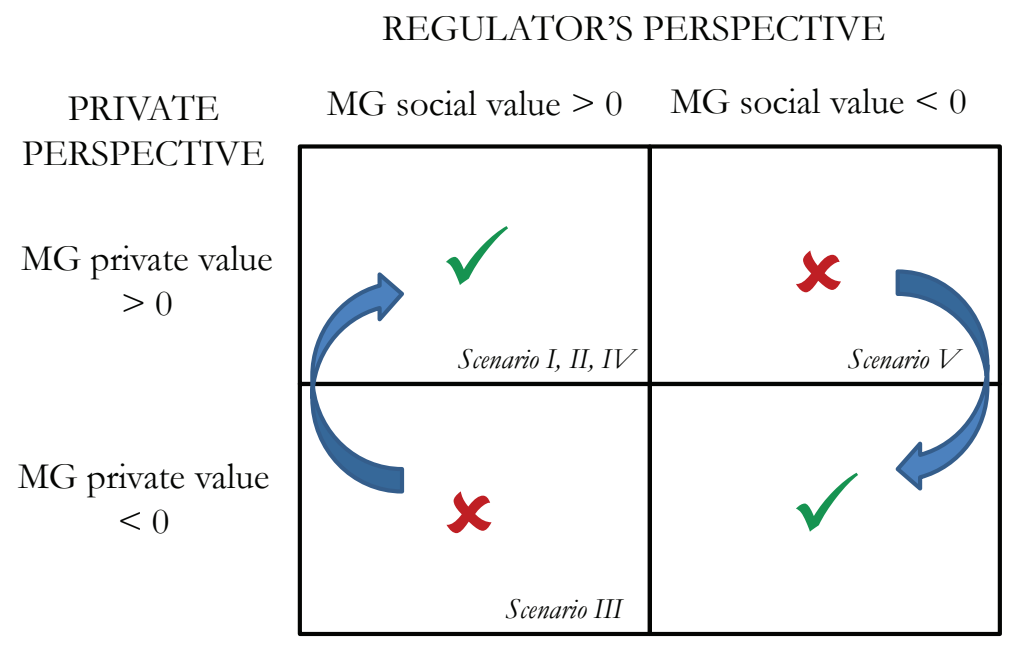

In the first three scenarios, the regulated power price (reflecting the utility's average cost of providing electricity) is below the marginal cost of utility-provided power. After MG introduction, utility sales decrease. For a given regulated price (i.e., the price before MG introduction), cost savings would be greater than revenue losses and the utility would earn a positive profit. As a result, the regulated price needs to be 
adjusted down after MG introduction to ensure that cost savings equal revenue losses.

Our base scenario, Scenario I, is defined by the assumptions and data presented in Section 2.3. The regulator correctly anticipates the timing of $\mathrm{MG}$ entry (i.e., there is no regulatory $\operatorname{lag}^{9}$ ) and electric rates are adjusted to account for MG introduction; as a result, the utility is made whole (i.e., it can recover all its costs). In Scenario II, the regulator sets the electric rates under the assumption that the utility is the only power supplier in the network, but a MG is built after the rate case (i.e., there is a regulatory lag). Scenarios I and II are in the upper left corner of Figure 2, since MG development has both a positive private and social value. The MG would be built, provided that the incumbent utility is made whole.

Scenario III assumes that the capital costs for the MG (in $\$ / \mathrm{kW}$ for generating capacity, and $\$ /$ unit for controllers and communication system) are three times higher than in the base case. Costs are tripled to create a situation in which the MG is unprofitable (i.e., its private value is negative), although its social value is positive, because the utility power displaced by the MG is more costly than the power provided by the MG. Regulatory intervention is needed to ensure an efficient market outcome, moving from the lower left to the upper left corner of Figure 2.

In the latter two scenarios, the regulated power price is above the utility's marginal cost of supplying power. This gives the utility an incentive to increase sales and discourage MG introduction, which instead reduces the utility's gross profit (defined as the difference between revenues from power sales and generation costs), as a result of lower sales. ${ }^{10}$ Given the regulated price before MG introduction, reduced sales decrease revenues by more than costs, creating a revenue adequacy problem for the utility. As a result, the regulated price needs to increase after MG introduction to ensure that the utility is made whole.

Scenario IV assumes that the utility's fixed costs are five times higher than in the base scenario (e.g., due to higher transmission and distribution costs). This value is chosen to obtain a scenario in which both private and social value of MG development are positive, but the rate increase adversely impacts nonmicrogrid customers. Finally, in Scenario V, the utility's fixed costs are seven times higher and the MG's capital costs are tripled, relative to the base case. This combination of cost increase results in positive gains for MG customers and the private investor, which are lower than the losses to other customers in the network due to the regulated price increase following microgrid introduction. Since the MG social value is negative, the regulator should ensure that a socially inefficient market outcome is not realized, moving from the upper right to the lower right corner of Figure 2.

\footnotetext{
${ }^{9}$ Regulatory lag occurs if the utility's costs change, but the PUC accounts for these changes with a delay in the rate-making process.

${ }^{10}$ This is a well-known consequence when average cost-based prices exceed marginal costs [65].
} 


\section{Results}

Our study investigates whether private and social benefits of microgrid development are aligned in a regulated electricity network, and the resulting effects on market prices, costs and benefits to various relevant stakeholders under different assumptions. Tables 6 and 7 present our results. In the first part of each table, we report the electricity prices. The regulated price, calculated based on cost of service, is the rate at which electricity is sold to residential customers at all nodes, with the exception of Coalition \{Private investor, D and $\{$ VIU, Private investor, D $\}$ : in these cases, the regulated price applies only to electric customers outside the MG, while MG customers pay an electricity price (also reported in the tables) such that the private gains (or losses) from the grand coalition are split equally with the private investor.

The value of each coalition is the sum of the present worth of the four annual surpluses of its players after the rate case has taken place. ${ }^{11}$ For example, in Scenario I the value of Coalition $\{$ VIU, D $\}$ is equal to the utility's surplus over the four-year period, plus the four-year surplus of consumers at node D. Since the VIU is compelled to offer service at average cost to all consumers, whether or not it cooperates with them, the consumer surplus for Coalition $\{$ VIU, D $\}$ is the same as that for Coalition $\{\mathrm{D}\}$.

We then present two sets of gains from the grand coalition. First, we calculate the gains of each party in the network (playing or not in the cooperative game) from the grand coalition, based on existing regulation: these are defined as the difference between the present value of each party's four-year payoff when the grand coalition is realized, and the present value of its four-year payoff when no MG is built. We refer to this set of gains as the "solution under existing regulation". The MG private value is the sum of gains from the grand coalition for the MG customers and the private investor; the MG social value is equal to its private value, plus the gains of all other customers in the network. The second set of gains refers more specifically to the players in the cooperative game: here, gains are defined as the difference between each player's Shapley value allocation (based on the value of the coalitions the player in question is part of) and the present value of its four-year payoff when no MG is built. Finally, we provide a range of gains from cooperation for each player; the core of the game is contained within the intersection of these ranges.

\subsection{Scenario I: base case}

The results of the base scenario are presented in Table 6. As noted in Section 2.5, the regulated power price, reflecting the utility's average cost of providing electricity, is below the marginal cost of utility-provided power, and MG introduction leads to a rate decrease in the grand coalition.

\footnotetext{
${ }^{11}$ As noted in Section 2.3.1, we assume that rate cases take place every four years.
} 
The cooperative game is superadditive, since the value of any joint coalition is greater than or equal to the sum of surpluses earned by the individual players or any union of disjoint coalitions. Therefore, under existing regulation a grand coalition would form: the utility is made whole by the regulator, and the private investor and consumers at D share the MG private value of $\$ 14,322 \mathrm{~K}$ in roughly equal parts, at a power price of $\$ 78 / \mathrm{MWh}$ in the MG. Although MG customers buy power at a higher price than what they paid to the utility, their consumer surplus increases when the MG is built, since heat from CHP operation of the MG is purchased at a $20 \%$ discount. In practice, the utility may not be able to fully recover its costs, if it incurs capital expenses to accommodate MG introduction that were not included in its revenue requirement during the rate case and may not be recovered in the future. Thus, the utility might oppose MG development in its service territory, and whether or not a grand coalition would form is ambiguous. This issue is discussed in Section 3.2 .

The MG social value, given by the sum of the MG private value and the surplus of other customers in the network, is also positive and equal to $\$ 37,279 \mathrm{~K}$ : to put the value in perspective, this gain corresponds to $\$ 1.6 / \mathrm{MWh}$ of annual power production in the network. Utility customers that are not part of the MG reap most of this benefit: due to lower rates induced by MG development, their surplus increases by $\$ 22,957 \mathrm{~K}$ over four years, exceeding the total gains of the private stakeholders in the grand coalition.

This scenario is in the upper left corner of Figure 2, having both a positive private and social value. Since the gains under existing regulation already are in the core of the cooperative game, no regulatory intervention is needed to ensure the formation of a grand coalition, provided that the utility is made whole.

\section{$3.2 \quad$ Scenario II: regulatory lag}

Scenario II in Table 6 differs from the base case in that it assumes that the regulator does not correctly account for MG development during the rate-making process, but a MG is built on the second year after the rate case. For this reason, the regulated price is the same for all coalitions. Moreover, while in the base case the utility adjusts the level of investments in new generation and distribution capacity based on whether or not the MG will be developed, in Scenario II the utility makes the same investment decisions in all coalitions, under the assumption that it will be the only electricity supplier in the network.

Relative to the base case, customers at node D gain less from the grand coalition for two reasons. First, in year 1 (before the MG is built) customers at node D satisfy their thermal load autonomously; second, once the MG enters the market, its installed generation capacity is slightly lower than in the base case, due to the reduced load determined by higher regulated prices. As a result, MG customers spend more (relative 
Table 6: Prices, value of coalitions and gains from cooperation - Base scenario

\begin{tabular}{|c|c|c|}
\hline & $\begin{array}{c}\text { Scenario I } \\
\text { Base }\end{array}$ & $\begin{array}{c}\text { Scenario II } \\
\text { Base, } \\
\text { Regulatory lag }\end{array}$ \\
\hline \multicolumn{3}{|c|}{ Regulated power price at each node served by the utility $(\$ / M W h)$} \\
\hline Coalition $\{$ VIU $\}$ & 66.9 & 66.9 \\
\hline Coalition $\{$ Private investor $\}$ & - & - \\
\hline Coalition $\{\mathrm{D}\}$ & 66.9 & 66.9 \\
\hline Coalition $\{$ VIU, D $\}$ & 66.9 & 66.9 \\
\hline Coalition \{VIU, Pr. inv. $\}$ & 65.7 & 66.9 \\
\hline Coalition $\{$ Pr. inv., D $\}$ & 65.6 & 66.9 \\
\hline Coalition $\{$ VIU, Pr. inv., D $\}$ & 65.7 & 66.9 \\
\hline Power price in the MG $(\$ / M W h)$ & 78.0 & 78.0 \\
\hline \multicolumn{3}{|l|}{ Value of each coalition $(\$ K)$} \\
\hline Coalition $\{$ VIU $\}$ & 0 & 0 \\
\hline Coalition \{Private investor & 0 & 0 \\
\hline Coalition $\{\mathrm{D}\}$ & 93,221 & 93,221 \\
\hline Coalition $\{$ VIU, D $\}$ & 93,221 & 93,221 \\
\hline Coalition \{VIU, Pr. inv. $\}$ & 0 & 8,530 \\
\hline Coalition $\{$ Pr. inv., D $\}$ & 105,412 & 102,286 \\
\hline Coalition $\{$ VIU, Pr. inv., D $\}$ & 107,543 & 121,507 \\
\hline \multicolumn{3}{|c|}{ Gains from $\{$ VIU, Pr. inv., D $\}$ relative to $\{$ VIU, D $\}$, under existing regulation $(\$ K)$} \\
\hline (a) Utility & 0 & 17,158 \\
\hline (b) Private investor & 6,493 & 5,285 \\
\hline (c) Customers at D & 7,829 & 5,841 \\
\hline (d) Other customers & 22,957 & 0 \\
\hline MG private value $(b+c)$ & 14,322 & 11,126 \\
\hline MG social value $(b+c+d)^{*}$ & 37,279 & 28,284 \\
\hline \multicolumn{3}{|c|}{ Gains from $\{$ VIU, Pr. inv., D $\}$ relative to $\{$ VIU, D $\}$, based on the Shapley value $(\$ K)$} \\
\hline Utility & 710 & 7,828 \\
\hline Private investor & 6,806 & 12,361 \\
\hline Customers at D & 6,806 & 8,096 \\
\hline \multicolumn{3}{|c|}{ Range of gains bounding the core $(\$ K)$} \\
\hline Utility & $(0,2,131)$ & $(0,19,220)$ \\
\hline Private investor & $(0,14,322)$ & $(0,28,285)$ \\
\hline Customers at D & $(0,14,322)$ & $(0,19,755)$ \\
\hline
\end{tabular}


to the base case) to self-supply the heat not provided by MG generators. The profits of the private investor are also reduced, because the MG only begins operations at year 2. Overall, the MG private value is lower than in the base case.

Contrary to Scenario I, the utility profits from the grand coalition in year 2,3 and $4(\$ 17,158 \mathrm{~K})$ because MG introduction reduces revenues less than total costs. Since the electricity price is unchanged, other customers in the network are unaffected by MG introduction in the short-run. Thus, the MG social value is also lower than in the base case. Given that the utility achieves positive gains from MG development, a grand coalition would be more likely to form than if the MG was accounted for in the rate-making process (and the VIU was simply made whole). Nevertheless, the MG social benefits are lower than in Scenario I and suboptimal investments take place, because too much capacity is installed in the network.

In practice, due to regulatory lag a utility may oppose the development of a socially beneficial MG by denying revenue streams to MG investors (e.g., by refusing to purchase MG energy and/or ancillary services offered to the grid [26]). One reason is that the utility may incur capital expenses (for example, associated with grid reinforcements and upgrades) that were not included in its revenue requirement during the previous rate case, and may not be recovered in the future. To avoid a market failure, one possibility would be to remunerate the utility for connecting microgrids to its network: for example, the regulator could include an additional revenue driver in the utility's revenue requirement, based on the amount of MG capacity connected to the network [66] or MG production fed into the distribution network [63]. The utility could also be guaranteed a higher rate of return on the utility's rate base, in case microgrids are connected to the grid, although this could encourage investment to inflate the capital base [67]. Policy makers are experimenting with new rate structures that remove or mitigate the disincentive to integrate microgrids into a regional grid: for example, pilot initiatives in Minnesota separate utilities' allowed rate of return from their revenues from energy sales. Similarly to decoupling policies to support energy efficiency programs, the goal of this approach is to ensure that utilities collect an agreed upon level of revenues, independent of actual sales. Finally, a better understanding of how microgrids contribute to power restoration in a regional grid may also lead to the introduction of performance-based mechanisms targeted at outage duration and frequency. The regulator might establish targets for some dimensions of performance (like number of outages and number of minutes per outage), together with financial incentives (penalties) to the utilities who perform better (worse) than the reference value. In this case, utilities would have an incentive not to oppose MG penetration, if this is beneficial for system reliability. This approach has been adopted in the U.K. to improve the quality of service of electric distribution companies [68]. 


\subsection{Scenario III: tripled MG's capital costs}

Scenario III in Table 7 assumes that the capital costs for the MG (in $\$ / \mathrm{kW}$ for generating capacity and $\$ /$ unit for controllers and communication system) are tripled, relative to the base case. Similarly to Scenario I, MG development determines a reduction in regulated electricity rates. Contrary to Scenario I, however, the game is not superadditive, as both the value of Coalition \{Private investor, D\} and the value of the grand coalition are lower than what could be achieved if the utility served the entire network. Building a MG would be unprofitable, with cumulative losses of about $\$ 1$ million over the four-year period. Thus, the MG private value is negative.

However, electric customers that are not served by the MG benefit from its introduction, due to the resulting decrease in electricity rates: therefore, the MG social value is positive. Note that the cooperative game in Scenario III has an empty core because, as noted in Section 2.1, participation of the private investor in the coalition formed by the other two players is not beneficial. Since the game is not superadditive, we do not calculate the Shapley value.

This scenario is in the lower left corner of Figure 2, with a negative private value and a positive social value. Under existing regulation a microgrid would not be built, resulting in a market failure; regulatory intervention should correct the inefficient outcome by making the microgrid profitable. Regulators may introduce incentives (such as feed-in premiums) on top of market prices to promote the MG and its efficient operation (e.g. higher production at peak hours), as recommended by Scheepers et al. [69]. The costs of investing in an increasingly decentralized system may be socialized across all customers in the utility's rate base. Regulators may also restructure rates to have MGs pay lower connection charges ${ }^{12}$ and/or demand charge rates, and impose higher remuneration rates for MG services to the grid.

Finally, utilities may install a meter to measure electricity flows to and from the MG, and offer compensation for net excess generation from the microgrid through net metering, or "running the meter backward". The MG would thus effectively be paid the retail price, which includes not only the cost of energy, but also the cost of transmission and distribution. The use of net metering as pricing incentive to promote DG has been criticized, based on the argument that DG providers (and customers) should not receive compensation for distribution services that continue to be provided by the utility and should pay their share of the utility's fixed costs for maintaining the distribution system [70, 71].

\footnotetext{
${ }^{12}$ Note that connection charges are not a variable in our analysis, but an external parameter equal to $10 \%$ of the annualized capital cost of the MG.
} 
Table 7: Prices, value of coalitions and gains from cooperation - Sensitivity analyses

\begin{tabular}{|c|c|c|c|}
\hline & $\begin{array}{l}\text { Scenario III } \\
\text { Tripled MG's } \\
\text { capital costs }\end{array}$ & $\begin{array}{c}\text { Scenario IV } \\
\text { Utility's fixed costs } \\
5 \text { times those in Base }\end{array}$ & $\begin{array}{c}\text { Scenario V } \\
\text { Utility's fixed costs } \\
7 \text { times those in Base \& } \\
\text { tripled MG's capital costs }\end{array}$ \\
\hline \multicolumn{4}{|c|}{ Regulated power price at each node served by the utility $(\$ / \mathrm{MWh})$} \\
\hline Coalition $\{$ VIU $\}$ & 66.9 & 124.8 & 169.8 \\
\hline Coalition $\{$ Private investor $\}$ & - & - & - \\
\hline Coalition $\{\mathrm{D}\}$ & 66.9 & 124.8 & 169.8 \\
\hline Coalition $\{$ VIU, D $\}$ & 66.9 & 124.8 & 169.8 \\
\hline Coalition \{VIU, Pr. inv. $\}$ & 66.1 & 124.7 & 169.8 \\
\hline Coalition $\{$ Pr. inv., D $\}$ & 65.9 & 125.1 & 172.8 \\
\hline Coalition $\{$ VIU, Pr. inv., D $\}$ & 65.8 & 125.3 & 171.2 \\
\hline Power price in the MG $(\$ / M W h)$ & 92.5 & 106.0 & 158.0 \\
\hline \multicolumn{4}{|l|}{ Value of each coalition $(\$ K)$} \\
\hline Coalition $\{$ VIU $\}$ & 0 & 0 & 0 \\
\hline Coalition $\{$ Private investor $\}$ & 0 & 0 & 0 \\
\hline Coalition $\{\mathrm{D}\}$ & 93,221 & 69,123 & 52,752 \\
\hline Coalition $\{$ VIU, D $\}$ & 93,221 & 69,123 & 52,752 \\
\hline Coalition \{VIU, Pr. inv. $\}$ & 0 & 5,366 & 0 \\
\hline Coalition $\{$ Pr. inv., D $\}$ & 91,739 & 103,433 & 85,620 \\
\hline Coalition $\{$ VIU, Pr. inv., D $\}$ & 92,321 & 107,446 & 70,960 \\
\hline \multicolumn{4}{|c|}{ Gains from $\{$ VIU, Pr. inv., D $\}$ relative to $\{$ VIU, D $\}$, under existing regulation $(\$ K)$} \\
\hline (a) Utility & 0 & 0 & 0 \\
\hline (b) Private investor & $-1,046$ & 20,261 & 8,283 \\
\hline (c) Customers at D & 146 & 20,910 & 9,924 \\
\hline (d) Other customers & 20,199 & $-8,727$ & $-18,840$ \\
\hline MG private value $(b+c)$ & -900 & 41,171 & 18,207 \\
\hline MG social value $(b+c+d)$ & 19,299 & 32,444 & -633 \\
\hline \multicolumn{4}{|c|}{ Gains from $\{$ VIU, Pr. inv., D\} relative to $\{$ VIU, D $\}$, based on the Shapley value $(\$ K)$} \\
\hline Utility & - & 1,436 & - \\
\hline Private investor & - & 19,867 & - \\
\hline Customers at D & - & 19,867 & - \\
\hline \multicolumn{4}{|c|}{ Range of gains bounding the core $(\$ K)^{*}$} \\
\hline Utility & $(0,582)$ & $(0,4,012)$ & $(0,-14,660)$ \\
\hline Private investor & $(0,-899)$ & $(0,38,322)$ & $(0,18,207)$ \\
\hline Customers at D & $(0,-899)$ & $(0,32,956)$ & $(0,18,207)$ \\
\hline
\end{tabular}
* In the range of gains bounding the core, an upper bound lower than the lower bound for one or more players indicates that
the core is empty. 


\subsection{Scenario IV: utility's fixed costs five times higher than in Scenario I}

Scenario IV in Table 7 assumes that the utility's fixed costs are about five times higher than those in the base case. The regulated power price is higher than the utility's marginal cost of electricity. This introduces a distortion and, as noted in Section 2.5, sets off a spiral of rising rates due to MG introduction.

The game is superadditive, and the value of Coalition $\{$ VIU, Private investor, D $\}$ is greater than that of any other coalition; therefore, under existing regulation a grand coalition would form, if the utility is made whole by the regulator. Building a MG is profitable for the private investor and increases the surplus of consumers at node D. The MG social value is also positive; however, contrary to Scenario I, utility customers not served by the MG are worse off, with a negative surplus of $\$ 8,727 \mathrm{~K}$ over the four-year period, due to the rate increase induced by MG introduction.

Under the assumptions of this scenario, MG entry is desirable because it increases economic efficiency (i.e., the scenario is in the upper left corner of Figure 2). However, our results highlight that the introduction of a socially efficient MG may also have negative price effects on customers that are not part of the distributed system. One possible way of compensating these customers for their surplus loss is through cross subsidization (e.g., by raising the price of electricity within the MG in order to subsidize penalized customers in the rest of the network).

\subsection{Scenario V: utility's fixed costs seven times higher than in Scenario I and tripled MG's capital costs}

Scenario $\mathrm{V}$ in Table 7 combines elements of the previous two scenarios, because it assumes both tripled

MG's capital costs and higher utility's fixed costs, relative to the base case. Regulated rates are above the marginal cost of power provided by the utility, and, similarly to Scenario IV, MG development determines an increase in the utility's rates in both Coalition \{Private investor, D\} and the grand coalition.

Contrary to Scenario IV, however, the game is not superadditive, since the value of the grand coalition is lower than what could be achieved by the coalition between the private investor and MG customers: therefore, the utility's marginal contribution to the grand coalition is negative. The reason is that the high regulated price creates an incentive to build more MG capacity in Coalition \{Private investor, D\}, so that the MG satisfies most of the power consumed at node D and imports are limited. On the other hand, in the grand coalition the MG has lower generating capacity, imports more (at a regulated price exceeding the one in the MG) and consumers spend more to self-supply the heat not provided by MG generators. As a result, the 
sum of surpluses for the consumers and the private investor in the grand coalition is lower than what the two players could achieve in their joint coalition.

Provided that the utility is made whole by the regulator, a grand coalition would form, with the private investor and consumers at D splitting the MG private value in roughly equal parts, at a power price of $\$ 158 /$ MWh in the MG. However, MG development is not socially desirable, with a negative social value of $-\$ 633 \mathrm{~K}$, because the surplus loss of customers not served by the MG (due to the resulting rate increase) exceeds the MG private value. Note that this game has an empty core because the utility's participation in the coalition of private investor and customers at node D is not beneficial. Similarly to Scenario IV, we do not calculate the Shapley value because the game is not superadditive.

This scenario is positioned in the upper right corner of Figure 2. Under existing regulation, a microgrid would be built (since it is profitable for the private investor and consumers at node D), resulting in a market failure due to its negative social value. Regulatory intervention should then correct the inefficient outcome. Vetoing MG development could be hard, unless the MG was regulated as an electric utility. One possibility would be to implement a rate reform that bases regulated prices on marginal rather than average costs, or includes two-part tariffs. On the other hand, a publicly-owned regulated utility may block MG development by imposing higher connection charges or refusing to remunerate the MG for the services offered to the grid.

\section{Conclusions}

This paper considers decision-making concerning design and operations of a microgrid in a market context in which retail price regulation may significantly distort those decisions and impact the distribution of costs and benefits among four sets of market parties: the microgrid developer, microgrid customers, an electric utility regulated based on cost of service, and customers not participating in the microgrid. Most of the existing literature on microgrids focuses on either technical issues of control and coordination, or on optimal design and operation from the point of view of just the microgrid developer and its customers, without considering market design issues or impacts on the rest of the market. In contrast, we examine how market rules influence the efficiency of microgrid development. Market interactions are assessed in the framework of cooperative game theory, assuming exchangeable utility and full public information, under alternative sets of assumptions.

Even though our study considers a stylized power system, it offers insights to energy regulators and policy 
makers on how to efficiently promote microgrids and what market failures should be addressed in order to maximize the benefits of microgrid development to the market. Our main findings can be summarized as follows.

First, average cost pricing does not necessarily hamper the realization of a socially efficient microgrid, as long as the utility can recover all costs, including those related to microgrid introduction (Scenario I). However, the misalignment between social welfare maximization and private objectives could result in inefficient market outcomes. For example, when regulated rates are below the marginal costs of utilityprovided power, a microgrid might not be built if high capital costs make it unprofitable, even if it is economically efficient. This case is illustrated in Scenario III. Alternatively, if retail rates are above marginal costs of power supplied by the utility, a microgrid may be profitable and beneficial for its customers, who experience a reduction in their energy bill due to cogeneration, but socially inefficient if these gains are more than offset by welfare losses of other customers in the network. This case is presented in Scenario V. An energy regulator could facilitate the realization of efficient market outcomes through side payments among the parties in the network, or rate reform that bases regulated prices on marginal rather than average costs, or includes two-part tariffs.

Second, it is ambiguous whether cooperation between the microgrid and the utility would occur, if the latter is not made whole. This would be the case, for example, if the regulator did not correctly anticipate the timing of microgrid introduction and did not account for it in the rate-making process, as shown in Scenario II. Although the utility will not oppose microgrid introduction if it expects positive profits, social benefits associated with microgrid development could be lower and suboptimal investments may take place, relative to when there is no regulatory lag. The regulator should ensure that the utility does not prevent the realization of socially beneficial microgrids: this could happen if the utility set very high connection charges or refused to remunerate services to the grid. To this end, possible incentives discussed in the paper include revenue bonuses for microgrid connections, higher rates of return on the utility's asset base and incentive mechanisms targeted at various dimensions of performance (like number of outages and number of minutes per outage).

Finally, the benefits of microgrid introduction may not be fully internalized by the private parties who would consider developing a microgrid. For instance, utility customers who are not served by the microgrid could reap most of those benefits, if microgrids result in lower regulated electric rates for all. However, when electric rates are above the marginal cost of power provided by the utility, introducing microgrids can instead raise rates, and the resulting economic losses to utility customers might exceed the economic gains to the 
microgrid owner and its consumers. 


\section{Appendix A - Model formulation}

This Appendix presents the optimization models for the coalitions in Section 2.3. We use a DC load flow approximation for the transmission grid, with resistance losses varying as a quadratic function of flows [72]. The models are stated generally, with $j$ representing the generators, $i$ and $k$ the transmission nodes, $l$ the distribution nodes where a MG could be installed. The load of customers that could not potentially be served by a MG enters the equations as load at transmission node $i$ (although these customers would be connected at lower voltage levels); on the other hand, the load of customers that could potentially be served by a MG enters the equations as load at distribution node $l$. The models are formulated for $T$ load periods, with $H_{t}$ hours in each period. Variables are in lower case and parameters in upper case; the nomenclature in Appendix B provides a list of variable and parameter definitions.

\section{A.1 Coalition $\{V I U\}$}

The utility's problem statement is as follows:

$$
\begin{aligned}
\max \Pi_{V I U}= & \sum_{t} H_{t}\left[P^{e}\left(\sum_{i} s_{V I U, i t}^{e}+\sum_{l} s_{V I U, l t}^{e}\right)-\sum_{i} \sum_{j}\left(M C_{V I U, i j t}^{e}+O M_{V I U, i j t}^{e}+\right.\right. \\
& \left.\left.+P^{c o_{2}} E_{V I U, i j t}\right) q_{V I U, i j t}^{e}\right]-C^{r} q_{V I U}^{r}-C^{d}-C^{g}-C^{r p}-C^{e a}-R O I^{e a}
\end{aligned}
$$

subject to:

$$
\begin{aligned}
& \sum_{j} q_{V I U, i j t}^{e}+\sum_{k \in A_{i}}\left[f_{k i t}\left(1-\operatorname{Loss}_{k i} f_{k i t}\right)-f_{i k t}\right]-\sum_{l \in A_{i}} f_{i l t} \geq L_{i t}^{e} \quad \forall i \in I, \forall t \in T \\
& \sum_{k \in A_{l}}\left[f_{k l t}\left(1-\operatorname{Loss}_{k l} f_{k l t}\right)\right] \geq L_{l t}^{e} \quad \forall l \in L, \forall t \in T \\
& \sum_{i k} R_{i k} S_{i k}\left(f_{i k t}-f_{k i t}\right)=0 \quad \forall t \in T \\
& q_{V I U, i j t}^{\text {or }} \leq R R_{V I U, i j} \quad \forall i \in I, \forall j \in J_{\text {old }}, \forall t \in T \\
& q_{V I U, i j t}^{\text {or }} \leq R R_{V I U, i j} \quad \forall i \in I, \forall j \in J_{\text {new }}, \forall t \in T \\
& q_{V I U, i j t}^{e}+q_{V I U, i j t}^{\text {or }} \leq C a p_{V I U, i j} \quad \forall i \in I, \forall j \in J_{\text {old }}, \forall t \in T \\
& q_{V I U, i j t}^{e}+q_{V I U, i j t}^{\text {or }} \leq n e w C a p_{V I U, i j} \quad \forall i \in I, \forall j \in J_{\text {new }}, \forall t \in T
\end{aligned}
$$




$$
\begin{aligned}
& \text { newCap }_{V I U, i j} \leq \operatorname{MaxCap}_{V I U, i j} \quad \forall i \in I, \forall j \in J_{\text {new }} \\
& q_{V I U, i j}^{b}=\text { newCap}_{V I U, i j} \quad \forall i \in I, \forall j \in J_{\text {new }} \\
& n e w C B \geq \frac{q_{V I U, t^{\text {peak }}}^{r p}}{U S^{c b}}-C B \\
& \sum_{i} \sum_{j \in J_{\text {old }}} \operatorname{Cap}_{V I U, i j}+\sum_{i} \sum_{j \in J_{\text {new }}} n e w C a p_{V I U, i j}+q_{V I U}^{r} \geq \sum_{i} \sum_{j} q_{V I U, i j p^{\text {peak }}}^{e}(1+R M) \\
& \sum_{i} \sum_{j} q_{V I U, i j t}^{o r} \geq \operatorname{ORM}\left(\sum_{i} L_{i t}^{e}+\sum_{l} L_{l t}^{e}\right) \quad \forall t \in T \\
& \sum_{i} \sum_{j \in J_{\text {new }}} q_{V I U, i j}^{b} \geq B M \sum_{i} \sum_{j \in J_{\text {old }}} C a p_{V I U, i j} \\
& q_{V I U, t}^{r p} \geq\left(\sum_{i} L_{i t}^{e}+\sum_{l} L_{l t}^{e}\right) \sqrt{\left(\frac{1}{\alpha^{2}}-1\right)} \quad \forall t \in T \\
& -T_{i k} \leq\left(f_{i k t}-f_{k i t}\right) \leq T_{i k} \quad \forall i, k \in I, \forall t \in T \\
& -D_{k l}-d e_{k l} \leq f_{k l t} \leq D_{k l}+d e_{k l} \quad \forall k \in I, \forall l \in L, \forall t \in T \\
& C^{d}=\frac{U C^{d} \sum_{k l} d e_{k l}}{A^{d}} \\
& C^{g}=\frac{U C^{g} \sum_{i} \sum_{j \in J_{n e w}} n e w C a p_{V I U, i j}}{A^{g}} \\
& C^{r p}=\frac{U C^{c b} n e w C B}{A^{c b}}
\end{aligned}
$$

Non-negativity constraints apply to the decision variables $q_{V I U, i j t}^{e}, f_{i k t}, f_{k l t}, q_{V I U, t}^{r p}, q_{V I U}^{r}, q_{V I U, i j t}^{o r}, d e_{k l}$, newCB and newCap ${ }_{V I U, i j}$. The utility's goal (4) is to maximize profit, equal to revenues from power sales at all nodes, minus costs for generation, reserves and new installed capacity. Depreciation expenses and allowed return on investment on existing assets are included in the objective function for consistency with the rate-making process, as they are part of the utility's revenue requirement.

Equations (5) and (6) account for Kirchhoff's Current Law (KCL), applied, respectively, to each transmission node and distribution node of the network. $f_{i k t}$ is the export flow from transmission node $i$ to transmission node $k$ in period $t$, while $f_{i l t}$ is the export flow from transmission node $i$ to distribution node $l$ in period $t . f_{k i t}\left(1-\operatorname{Loss}_{k i} f_{k i t}\right)$ represents the import flow, net of losses. Note that no generation occurs at the distribution nodes and no power is exported from them. Equation (7) represents Kirchhoff's Voltage Law (KVL) constraint, defined for the mesh (or loop) connecting the transmission nodes. 
Equations (8) and (9) limit the operating reserve provision of existing and new generators to be less than or equal to their ten-minute ramp rate. Equations (10) and (11) ensure, respectively for existing and new generators, that the sum of produced electricity and operating reserves is less than available capacity, while (12) constrains the capacity of each new generator to its maximum size. Equation (13) equals the black-start capability of each new generator to its capacity. In our setting, only new generators can provide black-start; additionally, all new generators can black-start, since they are of the same type. The number of new capacitor banks needed by the utility (14) is determined by the reactive power peak requirement of the network, divided by each capacitor's size, minus existing capacitors.

Equation (15) is the installed reserve margin requirement: existing and new capacity, plus reserves, have to be greater than or equal to peak generation in the network, plus a reserve margin requirement. Equation (16) is the operating reserve requirement in the network: the sum of the operating reserves has to be greater than or equal to total load, multiplied by an operating reserve margin. The model relies on the simplifying assumption that operating reserves do not have to be procured zonally: there is only one constraint for the entire system, and transmission constraints are ignored. Equation (17) is the black-start requirement in the network: total new generation capacity has to be sufficient to start a fraction of the existing capacity, defined by the black-start margin. Equation (18) is the reactive power requirement in the network: in every period $t$, the VIU has to provide an amount of reactive power which is greater than or equal to the network's load, times a coefficient accounting for the average power factor in the network $(\alpha)$.

Equations (19) and (20) constrain, respectively, the transmission and distribution flow on a given arc; only distribution arcs (but not transmission arcs) can be expanded in our formulation. Finally, equations (21) to (23) define three terms in the objective function: the annualized capital cost of distribution grid expansion, the annualized capital cost of new central generation capacity and the annualized capital cost of new capacitor banks.

\section{A.2 Coalition $\{D\}$}

The problem statement of the consumers at node $\mathrm{D}$ is as follows:

$$
C S_{l}=\sum_{t} H_{t}\left[\sum_{l} \int_{0}^{L_{l t}^{e}}\left(I_{l}-S_{l} q\right) d q-P^{e} \sum_{l} s_{V I U, l t}^{e}-P_{\text {Resid }}^{g a s} \sum_{l} q_{R e s i d, l t}^{g a s}\right]-C O_{R e s i d}
$$

The consumers' objective is to maximize their surplus, given by the gross benefit associated with electricity consumption (i.e., the integral of their demand curve for energy), minus expenditures for electricity and heat 
generation, and minus the cost of a three-hour per year power interruption. The latter cost is eliminated for consumers at $\mathrm{D}$ if a coalition with a private microgrid investor is entered into.

\section{A.3 Coalition \{VIU, Private investor $\}$}

The problem statement of the combined problem for the utility and the private investor is as follows:

$$
\begin{aligned}
\max \left(\Pi_{V I U}+\Pi_{P I}\right)= & \sum_{t} H_{t}\left[P^{e}\left(\sum_{i} s_{V I U, i t}^{e}+\sum_{l} s_{M G, l t}^{e}\right)-\sum_{i} \sum_{j}\left(M C_{V I U, i j t}^{e}+O M_{V I U, i j t}^{e}+\right.\right. \\
& \left.+P^{c o_{2}} E_{V I U, i j t}\right) q_{V I U, i j t}^{e}-\sum_{l} \sum_{j \in J_{\text {new }}}\left(M C_{M G, l j t}^{e}+O M_{M G, l j t}^{e}+\right. \\
& \left.\left.+P^{c o_{2}} E_{M G, l j t}\right) q_{M G, l j t}^{e}\right]-C^{r} q_{V I U}^{r}-C^{d}-C^{g}-C^{r p}-C^{m g}-C C-C^{e a}-R O I^{e a}
\end{aligned}
$$

subject to equations (7)-(14), (19), (21)-(23), plus:

$$
\begin{aligned}
& \sum_{j} q_{V I U, i j t}^{e}+\sum_{k \in A_{i}}\left[f_{k i t}\left(1-\operatorname{Loss}_{k i} f_{k i t}\right)-f_{i k t}\right]+\sum_{l \in A_{i}}\left[f_{l i t}\left(1-\operatorname{Loss}_{l i} f_{l i t}\right)-f_{i l t}\right] \geq L_{i t}^{e} \quad \forall i \in I, \forall t \in T \\
& \sum_{j \in J_{\text {new }}} q_{M G, l j t}^{e}+\sum_{k \in A_{l}}\left[f_{k l t}\left(1-\operatorname{Loss}_{k l} f_{k l t}\right)-f_{l k t}\right] \geq L_{l t}^{e} \quad \forall l \in L, \forall t \in T \\
& q_{M G, l j t}^{o r} \leq R R_{M G, l j} \quad \forall l \in L, \forall j \in J_{n e w}, \forall t \in T \\
& q_{M G, l j t}^{e}+q_{M G, l j t}^{o r} \leq n e w C a p_{M G, l j} \quad \forall l \in L, \forall j \in J_{\text {new }}, \forall t \in T \\
& \operatorname{newCap}_{M G, l j} \leq \operatorname{MaxCap} \operatorname{Ma}_{M, l j} \quad \forall l \in L, \forall j \in J_{\text {new }} \\
& q_{M G, l j}^{b}=\operatorname{newCap}_{M G, l j} \quad \forall l \in L, \forall j \in J_{\text {new }} \\
& q_{M G, l j t}^{r p}=q_{M G, l j t}^{e} \sqrt{\left(\frac{1}{\beta^{2}}-1\right)} \quad \forall l \in L, \forall j \in J_{\text {new }}, \forall t \in T \\
& \sum_{i} \sum_{j \in J_{\text {old }}} \operatorname{Cap}_{V I U, i j}+\sum_{i} \sum_{j \in J_{\text {new }}} \text { newCap }_{V I U, i j}+\sum_{l} \sum_{j \in J_{\text {new }}} \text { newCap } \operatorname{Ca}_{\mathrm{i}, l j}+q_{V I U}^{r} \geq \\
& \left(\sum_{i} \sum_{j} q_{V I U, i j t^{\text {peak }}}^{e}+\sum_{l} \sum_{j \in J_{\text {new }}} q_{M G, l j t^{\text {peak }}}^{e}\right)(1+R M) \\
& \sum_{i} \sum_{j} q_{V I U, i j t}^{o r}+\sum_{l} \sum_{j \in J_{\text {new }}} q_{M G, l j t}^{o r} \geq \operatorname{ORM}\left(\sum_{i} L_{i t}^{e}+\sum_{l} L_{l t}^{e}\right) \quad \forall t \in T \\
& \sum_{i} \sum_{j \in J_{\text {new }}} q_{V I U, i j}^{b}+\sum_{l} \sum_{j \in J_{\text {new }}} q_{M G, l j}^{b} \geq B M \sum_{i} \sum_{j \in J_{\text {old }}} C a p_{V I U, i j}
\end{aligned}
$$




$$
\begin{aligned}
& q_{V I U, t}^{r p}+\sum_{l} \sum_{j \in J_{\text {new }}} q_{M G, l j t}^{r p} \geq\left(\sum_{i} L_{i t}^{e}+\sum_{l} L_{l t}^{e}\right) \sqrt{\left(\frac{1}{\alpha^{2}}-1\right)} \quad \forall t \in T \\
& -D_{k l}-d e_{k l} \leq\left(f_{l k t}-f_{k l t}\right) \leq D_{k l}+d e_{k l} \quad \forall k \in I, \forall l \in L, \forall t \in T \\
& C^{m g}=\frac{U C_{M G}^{g} \sum_{l} \sum_{j \in J_{n e w}} n e w C a p_{M G, l j}+U C^{m g c c}+U C^{g c} n+U C^{l c} M+U C^{c s}}{A^{m g}} \\
& n=\frac{\sum_{l} \sum_{j \in J_{n e w}} n e w C a p_{M G, l j}}{U S^{g e n}}
\end{aligned}
$$

Non-negativity constraints apply to the decision variables $q_{M G, l j t}^{e}, q_{V I U, i j t}^{e}, f_{i k t}, f_{l k t}, f_{k l t}, q_{M G, l j t}^{r p}, q_{V I U, t}^{r p}, q_{V I U}^{r}$, $q_{M G, l j t}^{o r}, d e_{k l}$, newCap ${ }_{M G, l j}, q_{V I U, i j t}^{o r}$, newCap $p_{V I U, i j}, n$ and newCB. The goal of the coalition (25) is to maximize revenues from power sales at all nodes, minus costs for generation, reserves, new installed capacity and connection to the grid, depreciation expenses and allowed return on investment.

The revised constraints, relative to the ones presented for Coalition $\{\mathrm{VIU}\}$, account for the distributed generation units in the MG. Equations (26) and (27) are energy balances for each transmission and distribution node of the network. Unlike the utility's model, generation can occur at the distribution nodes; moreover, since the MG is fully integrated with utility operations, power can be exported from the MG to the rest of the grid. Equation (28) limits the operating reserve provision of MG generators to be less than or equal to their ten-minute ramp rate. Equation (29) ensures that the sum of produced electricity and operating reserves for each microgrid generator is less than its available capacity; (30) constrains the capacity of each new generator to its maximum size, and (31) equals the black-start capability of each new MG generator to its capacity. Equation (32) defines the reactive power provision of each MG generator at time $t$, proportionally to its power factor $\beta$. The requirements for installed reserve margin (33), operating reserves (34), black-start (35) and reactive power (36) account for the MG's contribution. Equation (37) constrains the distribution flows, including the possibility of power exports from the MG. Among the objective function term definitions, two new terms (compared to the utility's problem) are the annualized capital cost of the MG (38) and the number of generators in the MG (39). 


\section{A.4 Coalition $\{$ Private investor, D $\}$}

\section{A.4a Private investor's and customers' joint maximization problem}

The problem statement of the private investor and consumers at distribution nodes is as follows:

$$
\begin{aligned}
\max \left(C S_{l}\right. & \left.+\Pi_{P I}\right)=\sum_{t} H_{t}\left[\sum_{l} \int_{0}^{L_{l t}^{e}}\left(I_{l}-S_{l} q\right) d q-P_{\text {Resid }}^{\text {gas }} \sum_{l} q_{\text {Resid,lt }}^{\text {gas }}-P_{M G}^{g a s} \sum_{l} \sum_{j \in J_{\text {new }}} q_{M G, l j t}^{g a s}\right. \\
& \left.-\sum_{l} \sum_{j \in J_{\text {new }}}\left(O M_{M G, l j t}^{e}+P^{c o_{2}} E_{M G, l j t}\right) q_{M G, l j t}^{e}-P^{e} \sum_{k \in A_{l}} f_{k l t}\left(1-\operatorname{Loss}_{k l} f_{k l t}\right)\right]+ \\
& -C^{m g}-C C-C I-12\left[D C R\left(\sum_{l} \sum_{j \in J_{\text {new }}} q_{M G, l j t^{\text {pea }}}^{e}+\sum_{k \in A_{l}} f_{k l l^{\text {peak }}}\left(1-\text { Loss }_{k l} f_{k l t^{\text {pea }}}\right)\right)\right]
\end{aligned}
$$

subject to equations (30), (32), (38)-(39) plus:

$$
\begin{aligned}
& \sum_{j \in J_{\text {new }}} q_{M G, l j t}^{e}+\sum_{k \in A_{l}}\left[f_{k l t}\left(1-\operatorname{Loss}_{k l} f_{k l t}\right)\right] \geq L_{l t}^{e} \quad \forall l \in L, \forall t \in T \\
& \sum_{j \in J_{\text {new }}} q_{M G, l j t}^{h}+\eta q_{\text {Resid,lt }}^{\text {gas }}=L_{l t}^{h} \quad \forall l \in L, \forall t \in T \\
& q_{M G, l j t}^{e} \leq n e w C a p_{M G, l j} \quad \forall l \in L, \forall j \in J_{\text {new }} \\
& q_{M G, l j t}^{h} \leq q_{M G, l j t}^{e} E H R_{M G} \zeta \quad \forall l \in L, \forall j \in J_{\text {new }}, \forall t \in T \\
& q_{M G, l j t}^{e} E H R_{M G}=q_{M G, l j t}^{g a s} \quad \forall l \in L, \forall j \in J_{\text {new }}, \forall t \in T \\
& \sum_{l} \sum_{j \in J_{\text {new }}} q_{M G, l j t}^{r p}+s_{V I U, t}^{r p} \geq \sum_{l} L_{l t}^{e} \sqrt{\left(\frac{1}{\alpha^{2}}-1\right)} \quad \forall t \in T \\
& -D_{k l}-D E_{k l} \leq f_{k l t} \leq D_{k l}+D E_{k l} \quad \forall k \in I, \forall l \in L, \forall t \in T
\end{aligned}
$$

Non-negativity constraints apply to $q_{M G, l j t}^{e}, f_{k l t}, q_{M G, l j t}^{h}, q_{M G, l j t}^{r p}, q_{M G, l j t}^{g a s}$, newCap $p_{M G, l j}, q_{R e s i d, l t}^{g a s}, s_{V I U, t}^{r p}$ and $n$. The goal of the coalition (40) is to maximize the gross benefit of electricity consumption at the distribution nodes, minus costs for generation, power imports, new installed capacity and connection to the grid. Note that generation costs include in this case consumer expenditures for generating the heat not provided by MG generators. Moreover, demand charges are assessed against MG customers' peak power consumption, assumed to be the same during all months of the year.

Equation (41) accounts for Kirchhoff's Current Law, applied to the distribution nodes of the network. Generation can occur at the distribution nodes, but no power can be exported to the main grid. Equation (42) defines the heat balance at each distribution node: in every period $t$, the heat generated by the MG and the 
heat produced by the consumers (i.e., their natural gas consumption times the furnace efficiency) equal the heat load. Equation (43) ensures that MG generation is less than available capacity; unlike the corresponding equation in Coalition \{VIU, MG developer\}, (29), the MG provides no operating reserves. Equation (44) defines the amount of heat that can be produced by each MG generator at time $t$ to be less than or equal to power generation, times the useful heat output of the generator; in (45), the natural gas used by each MG generator is equal to its power output, multiplied by the electric heat rate. In (46), the reactive power provision of the MG, plus its reactive power purchases from the VIU, are greater than or equal to the MG's load, multiplied by a coefficient accounting for the average power factor in the network. Equation (47) limits imports along the distribution arc connecting the MG node to the rest of the grid. Unlike (20), distribution expansion represents only a parameter for the MG, since its amount is decided in the VIU's problem.

\section{A.4b Utility's maximization problem}

The utility's problem statement in the case of Coalition $\{$ Private investor, D $\}$ is as follows:

$$
\begin{aligned}
\max & \Pi_{V I U}=\sum_{t} H_{t}\left[P^{e}\left(\sum_{i} s_{V I U, i t}^{e}+\sum_{k \in A_{l}} F_{k l t}\left(1-\operatorname{Loss}_{k l} F_{k l t}\right)\right)\right. \\
& \left.-\sum_{i} \sum_{j}\left(M C_{V I U, i j t}^{e}+O M_{V I U, i j t}^{e}+P^{c o_{2}} E_{V I U, i j t}\right) q_{V I U, i j t}^{e}\right] \\
& +C I+12\left[D C R\left(\sum_{l} \sum_{j \in J_{\text {new }}} Q_{M G, l j t^{\text {peak }}}^{e}+\sum_{k \in A_{l}} F_{k l t^{p e a k}}\left(1-\operatorname{Loss}_{k l} F_{k l l^{p e a k}}\right)\right)\right] \\
& -C^{r} q_{V I U}^{r}-C^{d}-C^{g}-C^{r p}-C^{e a}-R O I^{e a}
\end{aligned}
$$

subject to equations (7)-(17), (19)-(23), plus:

$$
\begin{aligned}
& \sum_{j} q_{V I U, i j t}^{e}+\sum_{k \in A_{i}}\left[f_{k i t}\left(1-\operatorname{Loss}_{k i} f_{k i t}\right)-f_{i k t}\right]-\sum_{l \in A_{i}} F_{i l t} \geq L_{i t}^{e} \quad \forall i \in I, \forall t \in T \\
& q_{V I U, t}^{r p} \geq \sum_{i} L_{i t}^{e} \sqrt{\left(\frac{1}{\alpha^{2}}-1\right)}+S_{V I U, t}^{r p} \quad \forall t \in T
\end{aligned}
$$

Non-negativity constraints apply to $q_{V I U, i j t}^{e}, f_{i k t}, q_{V I U, t}^{r p}, q_{V I U}^{r}, q_{V I U, i j t}^{o r}$, newCap $p_{V I U, i j}, d e_{k l}$ and newCB.

The utility's goal (48) is to maximize revenues from power sales at the transmission nodes, power exports to the distribution nodes, customer and demand charges levied on the MG, minus costs for generation, reserves and new installed capacity, depreciation expenses and allowed return on investment.

Most of the constraints of this maximization problem are the same as the ones presented for Coalition 
$\{$ VIU\}, with a few exceptions. First, in the KCL constraint for the transmission nodes (49), power exports from transmission node $i$ to transmission node $l$ are given, since the utility supplies the difference between MG load and MG generation. Moreover, the utility does not account for the energy balance at the distribution nodes (i.e., there is no KCL constraint for the distribution nodes). Finally, in (50), the utility considers that at least part of the reactive power requirement at the distribution nodes is provided locally by the MG; this in turn affects its investment decisions on how many new capacitor banks should be built.

\section{A.5 Coalition $\{$ VIU, Private investor, D $\}$}

The problem statement in the grand coalition is as follows:

$$
\begin{aligned}
\max & \left.C S_{l}+\Pi_{P I}+\Pi_{V I U}\right)=\sum_{t} H_{t}\left[\sum_{l} \int_{0}^{L_{l t}^{e}}\left(I_{l}-S_{l} q\right) d q-P_{R e s i d}^{g a s} \sum_{l} q_{R e s i d, l t}^{g a s}\right. \\
& +P^{e} \sum_{i} s_{V I U, i t}^{e}-\sum_{i} \sum_{j}\left(M C_{V I U, i j t}^{e}+O M_{V I U, i j t}^{e}+P^{c o_{2}} E_{V I U, i j t}\right) q_{V I U, i j t}^{e} \\
& \left.-P_{M G}^{g a s} \sum_{l} \sum_{j \in J_{\text {new }}} q_{M G, l j t}^{g a s}-\sum_{l} \sum_{j \in J_{\text {new }}}\left(O M_{M G, l j t}^{e}+P^{c o_{2}} E_{M G, l j t}\right) q_{M G, l j t}^{e}\right] \\
& -C^{r} q_{V I U}^{r}-C^{d}-C^{g}-C^{r p}-C^{m g}-C C-C^{e a}-R O I^{e a}
\end{aligned}
$$

subject to equations (7)-(14), (19), (21)-(23), (26)-(39), (42), (44), (45), plus non-negativity constraints on the decision variables. The objective of the coalition (51) is to maximize the total surplus of the three players. This includes the gross benefit of electricity consumption at the distribution nodes and revenues from power sales at all nodes, minus costs for generation, reserves, new installed capacity and MG connection to the grid, depreciation expenses and allowed return on investment. 


\title{
Appendix B - Nomenclature
}

\author{
Indices \\ $i, k \quad$ transmission nodes in the network \\ $l \quad$ distribution node in the network, where a MG could be installed \\ j generator \\ $t \quad$ period \\ $t^{\text {peak }} \quad$ peak period \\ $i k \quad$ arc linking transmission node $i$ to transmission node $k$ \\ $k l \quad$ arc linking transmission node $k$ to distribution node $l$ \\ $l k \quad$ arc linking distribution node $l$ to transmission node $k$
}

Sets

$I$

$L$

set of transmission nodes

$J \quad$ set of generators

$J_{\text {old }} \quad$ set of existing generators

$J_{\text {new }} \quad$ set of new generators

T $\quad$ set of periods

$A_{i} \quad$ set of nodes adjacent to transmission node $i$

$A_{l} \quad$ set of nodes adjacent to distribution node $l$

Parameters

$\alpha$

$\beta$

$\eta$

$\zeta$

$A^{c b}$

$A^{d}$

$A^{g}$

$A^{m g}$

$B M$

$C^{r}$

$C^{e a}$

$\operatorname{Cap}_{V I U, i j}$ average power factor in the network

power factor of MG generators

furnace efficiency in the residential sector

useful heat output/electric heat rate of MG generators

annualization factor for capacitor banks, 1/year

annualization factor for distribution grid expansion, 1/year

annualization factor for new generation capacity, 1/year

annualization factor for the MG, 1 /year

black-start margin

cost of reserves, $\$ / \mathrm{MW} /$ year

depreciation expenses for existing assets, $\$ /$ year

existing capacity of central generator $j$ at node $i$, MW 


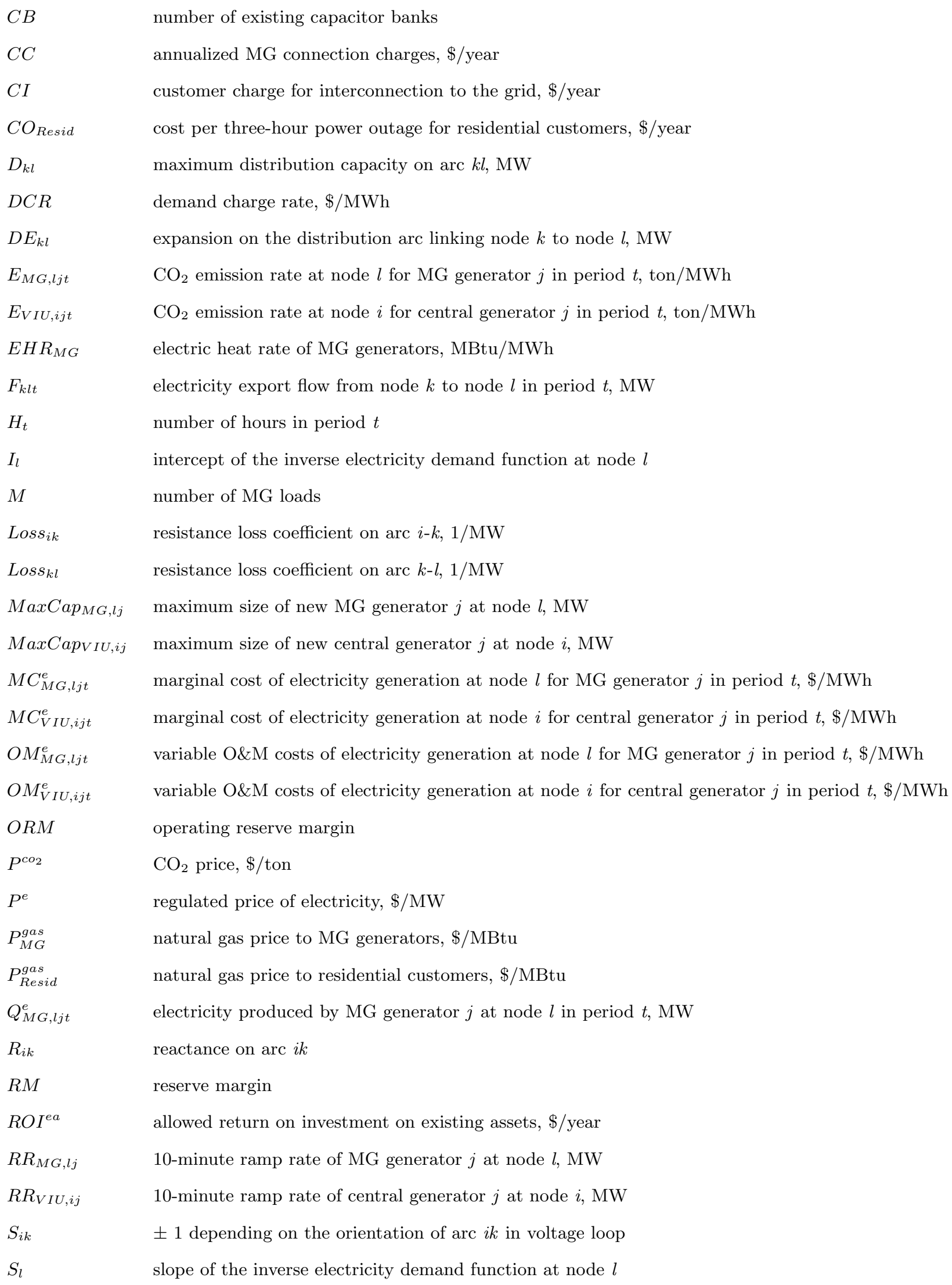


$S_{V I U, t}^{r p} \quad$ reactive power purchased by the MG from the VIU in period $t$, MVar

$T_{i k} \quad$ maximum transmission capacity on arc $i k$, MW

$U C^{c b} \quad$ capital cost of capacitor banks, $\$ /$ unit

$U C^{c s} \quad$ capital cost of MG communication system, $\$$

$U C^{d} \quad$ capital cost of distribution grid expansion, $\$ / \mathrm{MW}$

$U C^{g} \quad$ capital cost of new central generation capacity, $\$ / \mathrm{MW}$

$U C_{M G}^{g} \quad$ capital cost of new MG generation capacity, $\$ / \mathrm{MW}$

$U C^{g c} \quad$ capital cost of MG generator controller, $\$ /$ unit

$U C^{l c} \quad$ capital cost of MG load controller, $\$ /$ unit

$U C^{m g c c} \quad$ capital cost of MG central controller, \$/unit

$U S^{c b} \quad$ unit size of capacitor banks, MVar

$U S^{g e n} \quad$ unit size of MG generator, MW

Objective functions
$\Pi_{V I U}$
profit of the VIU, $\$$
$\Pi_{P I}$
profit of the private investor, $\$$
$C S_{l}$
surplus of residential customers at distribution node $l, \$$

\section{Decision variables}

$\begin{array}{ll}C^{d} & \text { annualized capital cost of distribution grid expansion, } \$ / \text { year } \\ C^{g} & \text { annualized capital cost of new central generation capacity, } \$ / \text { year } \\ C^{m g} & \text { annualized capital cost of the MG, } \$ / \text { year } \\ C^{r p} & \text { annualized capital cost of capacitor banks, } \$ / \text { year } \\ d_{k l} & \text { expansion on the distribution arc linking node } k \text { to node } l \text {, MW } \\ f_{i k t} & \text { electricity export flow from node } i \text { to node } k \text { in period } t, \mathrm{MW} \\ f_{k l t} & \text { electricity export flow from node } k \text { to node } l \text { in period } t, \mathrm{MW} \\ f_{l k t} & \text { electricity export flow from node } l \text { to node } k \text { in period } t, \mathrm{MW} \\ L_{i t}^{e} & \text { electricity load at node } i \text { and period } t, \text { MW } \\ L_{l t}^{e} & \text { electricity load at node } l \text { and period } t, \text { MW } \\ L_{l t}^{h} & \text { heat load at node } l \text { and period } t, \text { MBtu } \\ n & \text { number of MG generators } \\ n e w C a p_{M G, l j} & \text { new capacity of MG generator } j \text { at node } l, \text { MW } \\ n e w C a p_{V I U, i j} & \text { new capacity of central generator } j \text { at node } i, \text { MW } \\ n e w C B & \text { number of new capacitor banks }\end{array}$




$$
\begin{aligned}
& q_{M G, l j}^{b} \quad \text { black-start capacity provided by MG generator } j \text { at node } l \text {, MW } \\
& q_{V I U, i j}^{b} \text { black-start capacity provided by new central generator } j \text { at node } i \text {, MW } \\
& q_{M G, l j t}^{e} \text { electricity produced by MG generator } j \text { at node } l \text { in period } t, \mathrm{MW} \\
& q_{V I U, i j t}^{e} \text { electricity produced by central generator } j \text { at node } i \text { in period } t \text {, MW } \\
& q_{M G, l j t}^{g a s} \text { natural gas consumption by MG generator } j \text { at node } l \text { in period } t \text {, MBtu } \\
& q_{\text {Resid,lt }}^{\text {gas }} \text { natural gas residential consumption for heating at node } l \text { in period } t \text {, MBtu } \\
& q_{M G, l j t}^{h} \text { heat provided by MG generator } j \text { at node } l \text { in period } t \text {, MBtu } \\
& q_{M G, l j t}^{o r} \text { operating reserves provided by } \mathrm{MG} \text { generator } j \text { at node } l \text { in period } t \text {, MW } \\
& q_{V I U, i j t}^{o r} \text { operating reserves provided by central generator } j \text { at node } i \text { in period } t, \mathrm{MW} \\
& q_{V I U}^{r} \quad \text { reserves bought by the VIU, MW } \\
& q_{M G, l j t}^{r p} \text { reactive power provided by MG generator } j \text { at node } l \text { in period } t \text {, MVar } \\
& q_{V I U, t}^{r p} \quad \text { reactive power provided by the VIU in period } t \text {, MVar } \\
& s_{M G, l t}^{e} \text { electricity sold by the MG at node } l \text { in period } t, \mathrm{MW} \\
& s_{V I U, i t}^{e} \text { electricity sold by the VIU at node } i \text { in period } t, \mathrm{MW} \\
& s_{V I U, l t}^{e} \text { electricity sold by the VIU at node } l \text { in period } t, \mathrm{MW} \\
& s_{V I U, t}^{r p} \quad \text { reactive power purchased by the MG from the VIU in period } t \text {, MVar }
\end{aligned}
$$

\section{Appendix C - Solution approach}

The models presented in Appendix A are solved in IBM ILOG OPL 6.3. Each model is run for four load periods in each year (one peak period, two intermediate periods and one off-peak period), with each period representing several hours in a year (500 hours for the peak period, 3,400 hours for the intermediate periods, 1,460 hours for the off-peak period).

Due to demand elasticity, sales at each node depend on the regulated electricity price. At the same time, the regulated price is obtained by dividing the utility's revenue requirement by its total sales (equation (3)). Thus, finding the equilibrium price and quantities is a fixed point problem, ${ }^{13}$ which can be solved using the Gauss-Seidel method [73]. Our variable of interest is the regulated electricity price, $\mathrm{P}(\mathrm{Q})$. Given a continuous function mapping of $\mathrm{P}$ into itself, $\mathrm{P}(\mathrm{Q}(\mathrm{P}))$, the objective is to find a price $\mathrm{P}^{*}$ such that $\mathrm{P}^{*}=\mathrm{P}\left(\mathrm{Q}\left(\mathrm{P}^{*}\right)\right)$ and we achieve convergence to a fixed point. Convergence is not guaranteed, even if this exists; however, if the procedure converges, it will be to a fixed point. This iterative approach to finding a fixed point equilibrium has worked well in our study.

In Coalitions $\{V I U\},\{D\},\{V I U, D\},\{V I U$, Private investor $\}$ and $\{V I U$, Private investor, D $\}$, given

\footnotetext{
${ }^{13}$ Given a continuous function $\mathrm{f}: \mathrm{A} \rightarrow \mathrm{A}$ from a set $\mathrm{A} \in \mathrm{R}^{N}$ into itself, a vector $\mathrm{x} \in \mathrm{A}$ is a fixed point of $\mathrm{f}(\cdot)$ if $\mathrm{x}=\mathrm{f}(\mathrm{x})$ : that is, the vector is mapped into itself and remains "fixed".
} 
an initial value for $\mathrm{P}$, customers determine their consumption (equal to the utility's sales), Q(P), and the model is solved to obtain the optimal power dispatch in the network. Then, a new regulated electricity price, $\mathrm{P}(\mathrm{Q})$, is obtained, based on the new level of sales and costs. Given the price, consumers modify their decisions and the models are solved again to find the optimal power dispatch. The last two steps are repeated until convergence is achieved. Note that in Coalitions $\{$ VIU, Private investor $\}$ and $\{$ VIU, Private investor, D\} the regulated price is set to recover the utility's costs only, since the private investor is not subject to cost-of-service regulation.

Solving Coalition $\{$ Private investor, D $\}$ introduces an additional complexity: the utility and the microgrid take decisions separately, but these decisions influence each other. Their optimization models are solved iteratively. In the first step, given an initial value for the utility's regulated price, the microgrid optimizes electricity generation, imports from the main grid and reactive power production; the MG treats the utility's regulated price as fixed. In the second step, the utility optimizes power dispatch in the network, given the microgrid's quantity decisions; the VIU treats MG exports and generation as fixed. The microgrid successively updates its decisions based on the resulting regulated price for the utility. These steps are repeated until convergence is achieved.

Searching for the equilibrium can still be thought of as solving a fixed point problem, where $\mathrm{Q}_{1}(\mathrm{P})$ are the MG's power imports from the microgrid's problem. The regulated electricity price depends on Q, the total utility's sales, that include the microgrid's imports decisions $\left(\mathrm{Q}_{1}(\mathrm{P})\right)$, as well as sales at the other nodes of the network.

\section{References}

[1] Navigant Research. Microgrid Deployment Tracker 2Q15. Summary available from: https://www.navigantresearch.com/research/microgrid-deployment-tracker-2q15 [accessed Jan 2016].

[2] Lidula, N. W. A., Rajapakse, A. D. Microgrid research: a review of experimental microgrids and test systems. Renewable and Sustainable Energy Reviews 2011; 15: 186-202.

[3] Proietti, S., Arcioni, L., Desideri, U. Implementation of a system for the analysis and evaluation of advantages of distributed generation. Proceedings of GT 2006, ASME Turbo Expo 2006: Power for Land, Sea and Air; 2006, May 8-11; Barcelona, Spain. GT2006-90765. 
[4] Georgilakis, P. S., Hatziargyriou, N. D. Optimal distributed generation placement in power distribution networks: models, methods and future research. IEEE Transactions on Power Systems 2013; 28(3): $3420-8$.

[5] Stadler, M., Marnay, C., Siddiqui, A., Lai, J., Coffey, B., Aki, H. Effect of heat and electricity storage and reliability on microgrid viability: a study of commercial buildings in California and New York states. Berkeley (CA): Lawrence Berkeley National Laboratory, Environmental Energy Technologies Division; 2009. Report No.: LBNL-1334E.

[6] Ahn, S., Nam, S., Choi, J., Moon, S. Power scheduling of distributed generators for economic and stable operation of a microgrid. IEEE Transactions on Smart Grid 2013; 4(1): 398-405.

[7] Hawkes, A. D., Leach, M. A. Modelling high level system design and unit commitment for a microgrid. Applied Energy 2009; 86: 1253-65.

[8] Chen, Y., Lu, S., Chang, Y., Lee, T., Hu, M. Economic analysis and optimal energy management models for microgrid systems: a case study in Taiwan. Applied Energy 2013; 103: 145-54.

[9] Zhao, B., Zhang, X., Li, P., Wang, K., Xue, M., Wang, C. Optimal sizing, operating strategy and operational experience of a stand-alone microgrid on Dongfushan Island. Applied Energy 2014; 113: 1656-66.

[10] Silvente, J., Kopanos, G. M., Pistikopoulos, E. N., Espuña, A. A rolling horizon optimization for the simultaneous energy supply and demand planning in microgrids. Applied Energy 2015; 155: 485-501.

[11] Levron, Y., Guerrero, J. M., Beck, Y. Optimal power flow in microgrids with energy storage. IEEE Transactions on Power Systems 2013; 28(3): 3226-34.

[12] Comodi, G., Giantomassi, A., Severini, M., Squartini, S., Ferracuti, F., Fonti, A. et al. Multi-apartment residential microgrid with electrical and thermal storage devices: experimental analysis and simulation of energy management strategies. Applied Energy 2015; 137: 854-66.

[13] Gu, W., Wu, Z., Bo, R., Liu, W., Zhou, G., Chen, W., Wu, Z. Modeling, planning and optimal energy management of combined cooling, heating and power microgrids: a review. Electric Power and Energy Systems 2014; 54: 26-37.

[14] Su, W., Wang, J., Roh, J. Stochastic energy scheduling in microgrids with intermittent renewable energy resources. IEEE Transactions on Smart Grid 2014; 5(4): 1876-83. 
[15] Siddiqui, A., Marnay, C. Distributed generation investment by a microgrid under uncertainty. Berkeley (CA): Lawrence Berkeley National Laboratory, Environmental Energy Technologies Division; 2006. Report No.: LBNL-60592.

[16] Montuori, L., Alcázar-Ortega, M., Álvarez-Bel, C., Domijan, A. Integration of renewable energy in microgrids coordinated with demand response resources: economic evaluation of a biomass gasification plant by Homer Simulator. Applied Energy 2014; 132: 15-22.

[17] Justo, J. J., Mwasilu, F., Lee, J., Jung, J. AC-microgrids versus DC-microgrids with distributed energy resources: a review. Renewable and Sustainable Energy Reviews 2013; 24: 387-405.

[18] Che, L., Shahidehpour, M. DC microgrids: economic operation and enhancement of resilience by hierarchical control. IEEE Transactions on Smart Grid 2014; 5(5): 2517-26.

[19] Lo Prete, C., Hobbs, B. F., Norman, C. S., Cano-Andrade, S., Fuentes, A., von Spakovsky, M. R., Mili, L. Sustainability and reliability assessment of microgrids in a regional electricity market. Energy 2012; 41(1), 192-202.

[20] Cano-Andrade, S., von Spakovsky, M. R., Fuentes, A., Lo Prete, C., Mili, L. Upper level of a sustainability assessment framework for power system planning. Journal of Energy Resources Technology 2015; 137: 1-11.

[21] Khodaei, A., Shahidehpour, M. Microgrid-based co-optimization of generation and transmission planning in power systems. IEEE Transactions on Power Systems 2013; 28(2): 1582-90.

[22] Broder Hytowitz, R. Managing solar uncertainty in neighboring systems with stochastic unit commitment. M.Sc. thesis, 2013. Department of Electrical Engineering, Arizona State University.

[23] Marnay, C., Asano, H., Papathanassiou, S., Strbac, G. Economic and regulatory issues of microgrid implementation. IEEE Power \& Energy Magazine, May-June 2008. Available from: http://eetd.lbl.gov/publications/policymaking-microgrids-economic-and-regulatory-issuesof-microgrid-implementation [accessed Jan 2016].

[24] Wouters, C. Towards a regulatory framework for microgrids - the Singapore experience. Sustainable Cities and Society 2015; 15: 22-32.

[25] Van Hende, K., Wouters, C. The regulation of microgrids in liberalized electricity markets in the EU and East Asia. European Network Law and Regulation 2014; 3: 190-204. 
[26] Center for Energy, Marine Transportation and Public Policy at Columbia University. Microgrids: an assessment of the value, opportunities and barriers to deployment in New York state. Technical Report NYSERDA-10-35, 2010. Available from: http://web.mit.edu/cron/project/EESPCambridge/microgrid/NYS-Microgrids-Roadmap.pdf [accessed Jan 2016].

[27] New York State Department of Public Service, Staff Report and Proposal. Reforming the energy vision. 2014. Available from: http://www.dps.ny.gov/ [accessed Jan 2016].

[28] Burr, M. T., Zimmer, M. J., Meloy, B., Bertrand, J., Levesque, W., Warner, G., McDonald, J. D. Minnesota microgrids: barriers, opportunities, and pathways toward energy assurance. Microgrid Institute Technical Report. 2013. Available from: http://mn.gov/commerce-stat/pdfs/CHP\%20pdfs/MNMicrogrid-WP-FINAL-amended.pdf [accessed Jan 2016].

[29] Villareal, C., Erickson, D., Zafar, M. Microgrids: a regulatory perspective. California Public Utilities Commission Technical Report. 2014. Available from: http://www.cpuc.ca.gov/NR/rdonlyres/01ECA296-5E7F-4C23-85701EFF2DC0F278/0/PPDMicrogridPaper414.pdf [accessed Jan 2016].

[30] Costa, P. M., Matos, M. A., Peças Lopes, J. A. Regulation of microgeneration and microgrids. Energy Policy 2008; 36(10): 3893-3904.

[31] ISO/RTO Council. Available from: http://www.isorto.org/about/default [accessed Jan 2016].

[32] Joskow, P. L., Rose, N. L. The effects of economic regulation. In: Schmalensee, R., Willig, R. (Eds.), Handbook of Industrial Organization II, Amsterdam: Elsevier Science; 1989.

[33] Gately, D. Sharing the gains from regional cooperation: a game theoretic application to planning investment in electric power. International Economic Review 1974; 15(1): 195-208.

[34] Schotter, A., Schwödiauer, G. Economics and the theory of games: a survey. Journal of Economic Literature 1980; 18(2): 479-527.

[35] Kahan, J. P., Rapoport, A. Theories of coalition formation. New York: Psychology Press; 2014.

[36] Friedman, J. W. Game theory with applications to economics. Oxford: Cambridge University Press; 1985. 
[37] Gillies, D. B. Some theories on n-person games. Ph.D. dissertation, 1953. Department of Mathematics, Princeton University.

[38] Shapley, L. S., Shubik, M. Game theory in economics - Chapter 6: Characteristic function, core and stable set. 1973. Available from: http://www.rand.org/pubs/reports/R0904z6.html [accessed Jan 2016].

[39] Shapley, S. A value for n-person games. In: Kuhn H. W., Tucker, A. W. (Eds.), Contributions to the theory of games II. Annals of Mathematical Studies 28, Princeton: Princeton University Press; 1953.

[40] Kattuman, P. A., Bialek, J. W., Green, R. J. Allocating electricity transmission costs through tracing: a game-theoretic rationale. Operations Research Letters 2004; 32: 114-20.

[41] Contreras, J., Gross, G., Arroyo, J. M., Muñoz, J. I. An incentive-based mechanism for transmission asset investment. Decision Support Systems 2009; 47(1): 22-31.

[42] International Energy Agency. Projected costs of generating electricity. Paris: International Energy Agency; 2005.

[43] Mason, J. E., Archer, C. L. Baseload electricity from wind via compressed air energy storage (CAES). Renewable and Sustainable Energy Reviews 2012, 16: 1099-1109.

[44] U.S. Energy Information Administration. U.S. average cost of coal delivered for electricity generation, 2012. Available from: http://www.eia.gov/dnav/ng/hist/n3045us3A.htm [accessed Jan 2016].

[45] U.S. Energy Information Administration. U.S. Natural gas electric power price, 2012. Available from: http://www.eia.gov/dnav/ng/hist/n3045us3A.htm [accessed Jan 2016].

[46] Monitoring Analytics. 2010 Quarterly state of the market report for PJM: January through September. Section 5: capacity markets. Available from: http://www.monitoringanalytics.com/reports/PJM_State_of_the_Market/2010.shtml [accessed Jan 2016].

[47] Hadley, S. W., van Dyke, J. W., Poore, W. P., Stovall, T. K. Quantitative assessment of distributed energy resource benefits. ORNL Report. 2003. Available from: http://www.ornl.gov/w̃ebworks/cppr/y2001/rpt/116227.pdf [accessed Jan 2016].

[48] Eto, J., Stoft, S., Belden, T. The theory and practice of decoupling utility revenues from sales. Utilities Policy 1997, 6(1): 43-55. 
[49] Federal Energy Regulatory Commission. Form 1 - Electric Utility Annual Report, 2012. Available from: http://www.ferc.gov/docs-filing/forms/form-1/data.asp [accessed Jan 2016].

[50] Florida Public Service Commission. 2010 Statistics of the Florida electric utility industry. Available from: http://www.psc.state.fl.us/utilities/electricgas/statistics/statistics-2010.pdf [accessed Jan 2016].

[51] Paul, A. C., Myers, E. C., Palmer, K. L. A partial adjustment model of U.S. electricity demand by region, season and sector. RFF Discussion Paper. 2009. Available from: http://www.rff.org/Publications/Pages/PublicationDetails.aspx?PublicationID=20773 [accessed Jan 2016].

[52] U.S. Energy Information Administration. 2005 Residential Energy Consumption Survey. Available from: http://www.eia.gov/consumption/residential/data/2005/ [accessed Jan 2016].

[53] U.S. Energy Information Administration. U.S. price of natural gas delivered to residential customers, 2012. Available from: http://www.eia.gov/dnav/ng/hist/n3010us3m.htm [accessed Jan 2016].

[54] Campbell, R. J. Weather-related power outages and electric system resiliency. Congressional Research Service Report, 2012. Available from: http://fas.org/sgp/crs/misc/R42696.pdf [accessed Jan 2016].

[55] Centolella, P., Farber-DeAnda, M., Greening, L. A., Kim, T. Estimates of the value of uninterrupted service for the Mid-West Independent System Operator. Available from: http://www.hks.harvard.edu/hepg/Papers/2010/VOLL\%20Final\%20Report\%20to\%20MISO\%20042806.pdf [accessed Jan 2016].

[56] Marnay, C., Venkataramanan, G., Stadler, M., Siddiqui, A., Firestone, R., Chandran, B. Optimal technology selection and operation of commercial-building microgrids. Berkeley (CA): Lawrence Berkeley National Laboratory, Environmental Energy Technologies Division; 2007. Report No.: LBNL-62315.

[57] Li, F. F., Kueck, J., Rizy, T., King, T. A preliminary analysis of the economics of using distributed energy as a source of reactive power supply. ORNL Report. 2006. Available from: http://web.ornl.gov/sci/decc/Reports/Economics\%20of\%20DE\%20for\%20Reactive\%20Power\%20(ORNLTM-2006-014).pdf [accessed Jan 2016].

[58] Monitoring Analytics. 2010 Quarterly state of the market report for PJM: January through September. Section 6: ancillary service markets. Available from: 
http://www.monitoringanalytics.com/reports/PJM_State_of_the_Market/2010.shtml [accessed Jan 2016].

[59] Selecky, J., Iverson, K., Al-Jabir, A. Standby rates for combined heat and power systems. Report prepared by Brubaker \& Associates, Inc. and the Regulatory Assistance Project for Oak Ridge National Laboratory. 2014. Available from: http://www.raponline.org [accessed Jan 2016].

[60] Baltimore Gas and Electric. Electric service rates and tariffs for primary voltage service schedule (schedule P), effective 09/01/2010.

[61] Cossent, R., Gomez, T., Frias, P. Towards a future with large penetration of distributed generation: is the current regulation of electricity distribution ready? Regulatory recommendations under a European perspective. Energy Policy 2009; 37(3): 1145-55.

[62] Knight, R. C., Montez, J. P., Knecht, F., Bouquet, T. ELEP - Distributed generation connection charging within the European Union: Review of current practices, future options and European policy recommendations. 2005. Available from: http://www.ceer.eu/portal/page/portal/EER_HOME/EER_CONSULT/CLOSED\%20PUBLIC\%20CON SULTATIONS/ELECTRICITY/GGP\%20Transparency/RR/E06-PC-08-06a_ELEP050930_WP2_D21_Final_0.pdf[accessed Jan 2016].

[63] Frias, P., Gomez, T., Cossent, R., Rivier, J. Improvements in current European network regulation to facilitate the integration of distributed generation. Electrical Power and Energy Systems 2009, 31(9): 445-51.

[64] Castillo, A. Microgrid provision of blackstart in disaster recovery for power system restoration. Proceedings of the Fourth IEEE International Conference on Smart Grid Communications, Vancouver, Canada, October 21-24, 2013.

[65] Mankiw, N. G. Principles of economics. Mason: South-Western CENGAGE Learning; 2012.

[66] Jamasb, T., Neuhoff, K., Newbery, D., Pollitt, M. Long-term framework for electricity distribution access charges. Cambridge University Report for OFGEM. 2005. Available from: https://www.ofgem.gov.uk/ofgem-publications/44457/10146-cambridge.pdf [accessed Jan 2016].

[67] Averch, H., Johnson, L. L. Behavior of the firm under regulatory constraint. American Economic Review 1962; 52(5): 1052-69. 
[68] Joskow, P. L. Lessons learned from electricity market liberalization. The Energy Journal 2008; 23(7): $9-42$.

[69] Scheepers, M., Bauknecht, D., Jansen, J., de Joode, J., Gómez, T., Pudjianto, D., et al. Regulatory improvements for effective integration of distributed generation into electricity distribution networks. Energy Research Centre of the Netherlands Working Paper. 2007. Available from: http://www.ecn.nl/do cs/library/report/2007/e07083.pdf [accessed Jan 2016].

[70] Brown, A., Lund, L. Distributed generation: how green? How efficient? How well-priced? The Electricity Journal 2013; 26(3): 28-34.

[71] Edison Electric Institute. A policy framework for designing distributed generation tariffs. 2013. Available from: http://www.eei.org/issuesandpolicy/stateregulation/Pages/RateReform.aspx [accessed Jan 2016].

[72] Chao, H. P., Peck, S. Reliability management in competitive electricity markets. Journal of Regulatory Economics 1998; 14(2): 189-200.

[73] Hageman, L., Young, D. Applied iterative methods. New York: Academic Press; 1981. 